\title{
ON THE DEVELOPMENT OF THE EXTERNAL FORM OF THE HUMAN CEREBELLUM.
}

\author{
BY J. W. LANGELAAN. \\ Amsterdam.
}

THE great obstacle to the study of the morphology of the cerebellum lies in the nomenclature. In order to avoid misunderstanding, I propose to give first a table, containing the names of the grooves, fissures and lobes I intend to use. In choosing these names I have been as conservative as possible. I followed therefore the purely topographical method of human anatomy. This system recognises an upper and an under surface of the cerebellum and a posterior margin, where the two surfaces meet. The names of the fissures have been chosen in accordance with this orientation. I do not fancy the system will be satisfactory in general, but if it helps to avoid misunderstandings it will have performed its duty. It would be possible to invent an entirely new system of unequivocal terms to indicate the principal fissures of the human cerebellum. In the table preceding this research I shall add these new terms in brackets behind the older ones.

The general result of my research is that the human cerebellum at a certain period of its development is built up of ten lobes. Because these ten lobes comprise all the later parts of the adult cerebellum, I take them as the starting point for the division of the human cerebellum.

TABLE.

(1) Lobus vinculolingualis

Fissura prelingualis

(2) Lobus centro-alaris

Fissura precentralis [f. centrolingualis]

(3) Lobus culminolunatus

Fissura prelunata [f. culminocentralis]

(4) Lobus declivolunatus

Fissura superior anterior [f. declivoculminalis]

(5) Lobus foliosemilunaris

Fissura superior posterior [f. foliodeclivalis]

Fissura horizontalis [f. tuberofolialis]

(6) Lobus tuberosemilunaris

Fissura inferior posterior [f. pyramidotuberalis]

(7) Lobus pyramidobiventricus

Fissura inferior anterior [f. uvulapyramidalis]

(8) Lobus uvulatonsillaris

Fissura preuvularis [f. nodulo-uvularis]

(9) Lobus nodulofloccularis

(10) Lobus nodiolovelaris

Fissura prenodularis [f. nodiolonodularis] 
It follows also from this research that the vermis and the hemispheres during a certain stage of development are well-defined, separate parts of the cerebellum: hence it is necessary to discriminate between the fissures belonging to the vermis and those belonging to the hemispheres. But because most fissures of vermis and hemispheres later join together, it will be sufficient to add the term "pars mediana" to the name of the fissure to indicate the vermis part, and the term "pars lateralis" to indicate the hemispherical division of the furrow.

A cerebellum of the middle of the third month forms the starting point of the description. In this stage of development, the cerebellar plate (lamina cerebelli') has the form of a horseshoe, which embraces the brainstem. It is placed approximately perpendicular to the direction. of the stem, so that we may describe a superior, an inferior and a lateral surface in respect of the main direction of the stem.

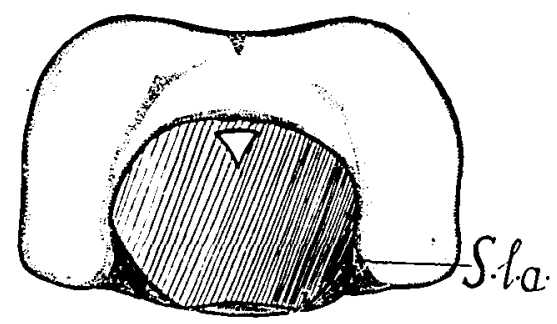

Fra. 1.-Superior surface of a cerebellum of the middle of the third month. The brain. stem is cut away at the level of the cerebellar plate. S.l.a., sulcus limitans ant.
Enlargement $\times 5$.

The superior surface of the cerebellar plate is nearly flat and separated by a shallow groove, the sulcus limitans cerebelli anterior, from the mesencephalon. Ventrally, the groove becomes a little deeper and broader (fig. 1). A very shallow depression, starting from the limiting groove, extends on either side over the upper surface of the cerebellar plate. Both depressions are curved towards the middle line, but in this stage of development do not yet meet there.

The superior surface passes continuously into the inferior surface. The greater part of this surface consists of a thin lamella (lamella cerebelli). Seen from the outside, it gives the impression that the lamina rapidly thins off into the lamella (fig. 2). The lamella on its posterior border is continued into the rhombencephalon. The transition of the lamella into the substance of the rhombencephalon

This name has been introduced by von Mihalcovics [13]. 
is marked by a groove, the sulcus limitans posterior. Along the ventral border of the cerebellar plate the posterior limiting groove continuously passes over into the anterior limiting groove. The limiting groove is filled up by embryonic connective tissue, so that the true configuration of the groove is not reproduced in my drawings. The lamella cerebelli is also covered by connective tissue, which could not be removed without tearing the membrane. Several details of the lamella, e.g., the plica chorioidea, are therefore not visible. ${ }^{1}$

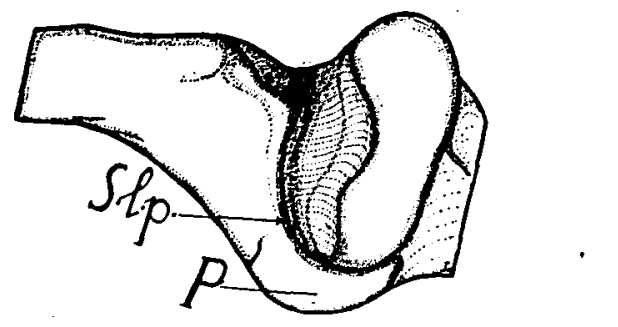

Frg. 2.-Lateral surface of a cerebellum of the middle of the third month. Samecerebellum as reproduced in fig. 1 . The lamella cerebelli is covered by embryonic connective tissue, so that the plica chorioidea and several other details could not be reproduced. $P .$, pons ; S.l.p., sulcus limitans post. Enlargement $\times 5$.

The transition of the cerebellar plate into the lamella is not situated at the posterior margin of the plate, but somewhat anterior to it, so that the posterior border of the plate protrudes freely into the ventricular cavity, covered by the lamella. In fig. 2 this part of the plate may be seen shining through the lamella. This state persists during the whole development of the cerebellum and even in the adult stage, though it is less evident from the middle of the third to the middle of the fifth month.

In the middle line the cerebellar plate is thin and transparent; this transparent spot is slightly depressed on the outer surface. Whether this depression really exists or is artificially formed by the fixation, I do not know. On the inner surface the cerebellar plate rapidly thins off towards the middle line. Hence we conclude that the middle line is a place of reduced growth in comparison with the adjoining regions of the plate. This conclusion seems to tell in favour of the view that the cerebellar plate is a structure of bilateral origin (His [9]). ${ }^{2}$ This thin and transparent place disappears pari passu with the enlargement of the

1 A more detailed description of this stage has been given by me in the "Anatomischer Anzeiger" [12].

2 A discussion of this question is to be found in $O$. Charnock Bradley [5]. 
plate, but even in a more advanced stage of the plate the region of the middle line is still slightly depressed on the inner surface.

Another thin spot exists on either side of the middle line. Here the posterior edge of the plate shows a little notch, which runs out into a shallow groove (fig. 3). By these two lateral grooves a median portion of the plate is demarcated, which later seems to form the vermis. The lateral grooves have first been observed and described by Kölliker [10].

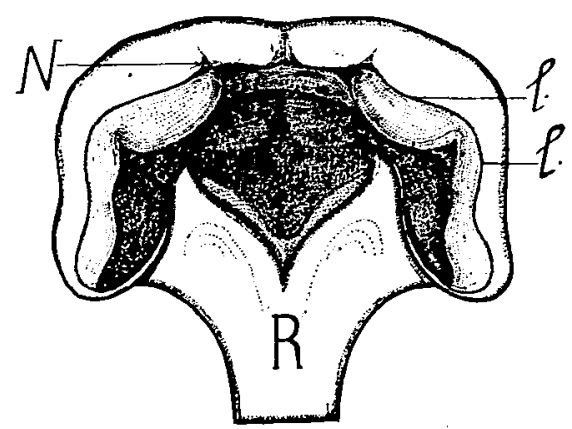

FIG. 3.-Inferior surface of a cerebellum of the middle of the third month. Same cerebellum as reproduced in figs. 1 and 2. The lamella cerebelli is torn off along the line $l, l$, so that the fourth ventricle is opened. The posterior border of the cerebellar plate is visible protruding into the ventricular cavity. $N$, notch in the cerebellar plate; $R$, rhombencephalon. Enlargement $\times 5$.

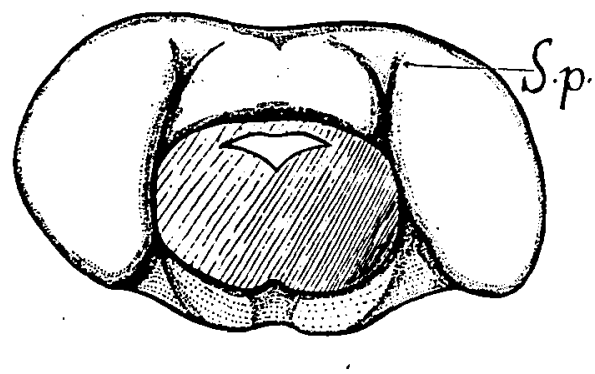

Fig. 4.-Superior surface of a cerebellum of the second half of the third montb. The brainstem is cut away at the level of the cerebellar plate. S.p., sulcus paramedianus. Enlargement $\times 5$.

The next stage is somewhat older, probably the second half of the third month. In this stage, the superior surface of the cerebellar plate is more convex and more distinctly marked off from the brainstem (fig. 4). The depression starting from the sulcus limitans has developed into a shallow'bifurcated groove. The medial branch of the groove curves towards the middle line, where they later join together. At the bottom of this shallow groove, the fissura superior anterior ${ }^{1}$ makes its appearance. The field limited from behind by this groove, becomes gradually slightly elevated. In consequence of this elevation it begins to project above the regions immediately adjoining the mesencephalon. In a somewhat older stage this relation is still more accentuated (fig. 5).

The little field in front of the elevated field is triangular, resting with its base upon the tectum mesencephali. In the beginning it is indistinctly

$$
\text { ' " Fissura prima'" of embryologists. }
$$


marked off from the elevated field; but somewhat later a fissure appears, the fissura prelunata, which divides the two fields. The base of the field is separated from the brain stem by a fairly deep groove, the fissura precentralis, which has partly developed from the anterior limiting groove. In the depth of this groove a small white ridge is visible, the first trace of the lingula.

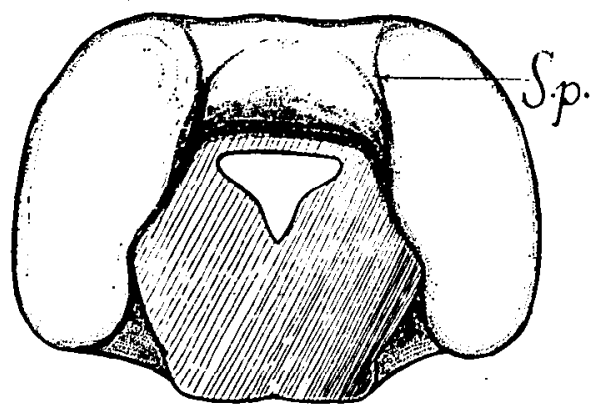

Fia. 5.-Superior surface of a cerebellum of the second half of the third month. This cerebellum is probably somewhat older than that reproduced in fig. 4 . The brainstem is cut away at the level of the cerebellar plate. S.p., sulcus paramedianus. Enlargement $\times 5$.

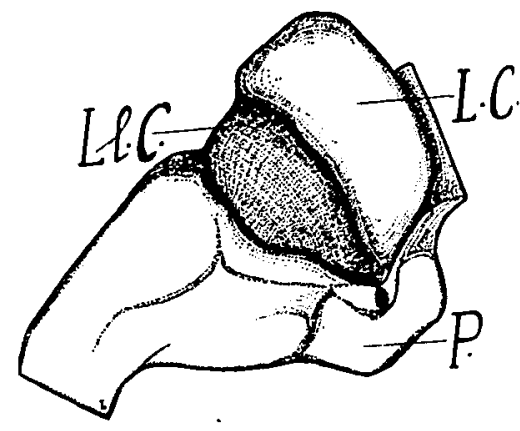

FIg. 6.-Lateral surface of the same cerebellum which is reproduced in fig. 4. The lamella cerebelli is covered by connective tissue, so that the details of the membrane could not be reproduced. L.C., lamina cerebelli ; Ll.C., lamella cerebelli; $P$, pons. Enlargement $\times 5$.

The lateral branch of the bifurcated groove runs in antero-posterior direction. The groove becomes flatter at this stage of development in the neighbourhood of the posterior border of the superior surface. This groove forms the origin of the sulcus paramedianus, which divides the vermis from the hemispheres. I have received the impression that the sulcus paramedianus develops from the lateral groove of Kölliker. The inferior surface has increased in size and the cerebellar plate seems to approach its completion (fig. 6). The posterior border of the plate still protrudes into the ventricular cavity, but this is no longer as evident as it was before.

The first grooves to appear upon the cerebellar surface seem to be formed by differences in growth between the regions adjoining the groove and those forming the bottom of the groove. This causes the grooves to be broad and shallow. Later, the formation of the grooves takes place by a more active process. In this case, the formation of the furrow is preceded by a proliferation of cells, in an antero-posterior direction, which is followed by the appearance of a transverse fissure, perpendicular upon the direction of the cell-proliferation. This process 
resembles in some respects cleavage. The sulcus paramedianus appears chiefly, if not exclusively, to be formed in the first manner, whilst the other fissures, by which the cerebellar plate is split up into ten lobes, are principally formed in the second way. Because the two processes in the beginning interfere, it is often difficult to state the exact moment at which a fissure arises. My own material tends to the conclusion, in agreement with Kölliker [10], Mihalcovics [13], Bradley [3, 4], and Bolk [2], that the furrowing begins first in the vermis, followed shortly by the cleavage of the hemispheres. The formation of the fissures in the vermis proceeds, at least in the beginning, independently of the formation of the fissures in the hemispheres. The sequence in which the fissures appear to take their origin in the vermis is: fissura precentralis, fissura superior anterior and fissura prenodularis, approximately at the same moment; next the fissura prelunata and the fissura preuvularis; lastly, the fissura inferior anterior and the fissura inferior posterior.

The hemispherical fissure, which first appears, is the pars lateralis of the fissura prenodularis, and this fissure is very soon followed by the lateral part of the fissura preuvularis. This fact is also stated by Bradley [3] for the rabbit and the pig, by Kölliker [10] for the rabbit, and in man by Smith [19], and by Stroud [22]. The fissure of the hemisphere appearing next is the pars lateralis of the fissura superior posterior. This latter furrow makes its appearance approximately simultaneously with the vermis portion of the fissuræ inferior anterior and inferior posterior. To sum up, I find, therefore, that the fissures of the vermis begin to form before those of the hemispheres; that the first fissures of the vermis arise approximately at the same time in the neighbourhood of its anterior and posterior borders. In the hemispheres, the furrowing in the neighbourhood of the posterior border precedes a little the furrowing near the anterior border.

The period of fissure formation of the cerebellar plate is only short, so that the differences in time between the moments at which the fissures appear are very small. For this reason inversions may probably occur in the sequence, by which the fissures make their appearance. Most observers, e.g., Smith $[17,19]$, extend the period of furrowing over several months. This opinion is probably the result of the fact that during the development of the cerebellum certain fissures may temporarily vanish and reappear.

The next stage belongs to the end of the third or the beginning of the fourth month. The superior surface shows clearly, at least in the 
case of the right half, the division of the cerebellum into a vermis and hemispheres (fig. 7). On the inferior surface the distinction is not yet so evident; this boundary is indicated by a shallow, partly interrupted, groove only (fig. 8).

The triangular field, which rests upon the tectum. mesencephali, has considerably increased in size. It is separated from the brainstem by a deep groove, the fissura precentralis. At the bottom of this groove there lies concealed the white prominence that forms the origin of the lingula. From behind, the triangular field is bounded by a fairly deep groove, the fissura prelunata. The triangular field itself is still confined to the vermis, but shortly afterwards the furrows limiting the field extend laterally into the hemispheres. The triangular field, with its hemispherical appendices, forms the lobus centro-alaris. The median division of this lobe, i.e., the triangular field, is the later lobulus centralis.

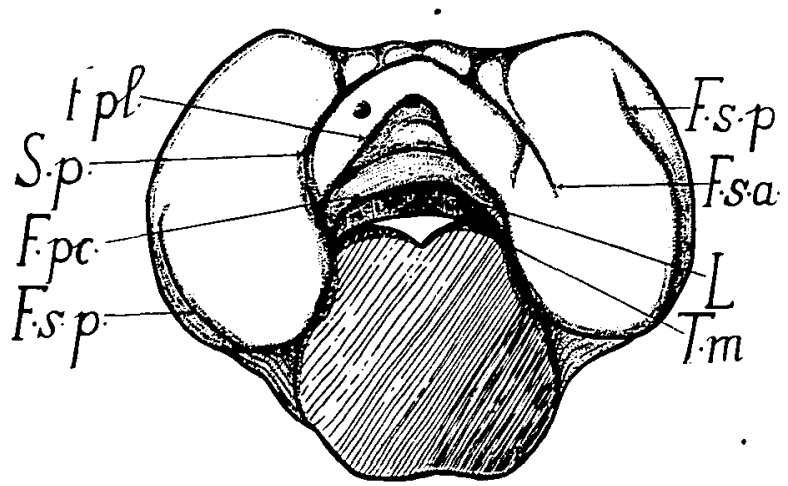

Fig. 7.--Superior surface of a cerebellum of the end of the third month or of the beginning of the fourth one. The brainstem is cut off. F'.pc., fissura precentralis : $F . p l$., fissura prelunata; $F . s . a$. , fissura superior ant. ; $F$.s.p., fissura superior post. ; L., lingula; $S . p$. , sulcus paramedianus ; T.m., tectum mesencephali. Enlargement $\times 5$.

At this early stage the lobulus centralis is already divided into two parts by a complete fissure of the second order. The superior division of the lobule shows the beginning of another secondary groove (fig. 7). These grooves are the first secondary grooves of the cerebellum to appear and they precede in their appearance the primary fissures of the central region of the cerebellum.

The prominent field situated behind and above the lobulus centralis is bordered from behind by a deep fissure, the pars mediana of the fissura superior anterior. At this stage of development it is the deepest fissure of the cerebellum and easily recognizable. Originally the fissura superior anterior belongs to the vermis, but on the left this groove 
penetrates through the sulcus paramedianus and begins to extend into the hemisphere. Here it remains a short groove, which does not reach the lateral hemispherical margin.

The next groove is the median part of the fissura inferior posterior. This groove belongs to the inferior surface and is at this stage strictly confined to the vermis (fig. 8). The next groove is the median part of the fissura inferior anterior, and this groove also fails to extend as yet into the hemisphere. The fissura preuvularis comes next. On the right, this groove is limited to the vermis, but on the left it already passes into the hemisphere. The hemispherical or lateral part of the fissura preuvularis arises independently, near the lateral margin of the hemisphere, grows medially and unites with the median division of the groove.

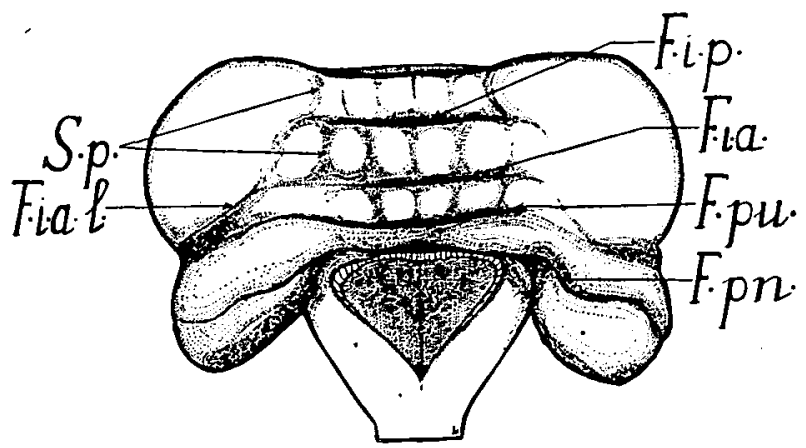

FIa. 8.-Inferior surface of a cerebellum of the end of the third month or of the beginning of the fourth one. Same cerebellum as reproduced in fig 7. F.i.a., fissura inferior ant., median part; F.i.a.l., fissura inferior ant., lateral part; F.i.p., fissura inferior posterior. $F^{\prime} . p n$., fissura prenodularis; $F . p u$, fissura preuvularis ; S.p., sulcus paramedianus. Enlargement $\times 5$.

The most posterior groove is the fissura prenodularis, which is also of double origin. The median part of this groove remains limited to the vermis. The lateral part takes its origin close to the lateral margin of the hemisphere, extends medially and then joins the median division in the neighbourhood of the sulcus paramedianus. Both divisions of this groove may arise at the same moment, but more often the median part precedes by a little the hemispherical part.

The last groove of this stage is the fissura superior posterior. This groove originates on the inferior surface of the hemisphere near the lateral border (fig. 9) ; growing medially, it reaches the superior surface (fig. 7). At the moment of its appearance this groove is not yet represented in the vermis, so that it forms the type of a purely hemi- 
spherical fissure. When this groove reaches the neighbourhood of the sulcus paramedianus, the first vestige of a furrow appears in the vermis. This furrow extends laterally and unites with the hemispherical division of the fissura superior posterior. Smith [19] and Bolk [2] also recognised the fact that the fissura superior posterior first originates in the hemisphere. The moment, however, at which Bolk believes that the groove arises is undoubtedly too late.

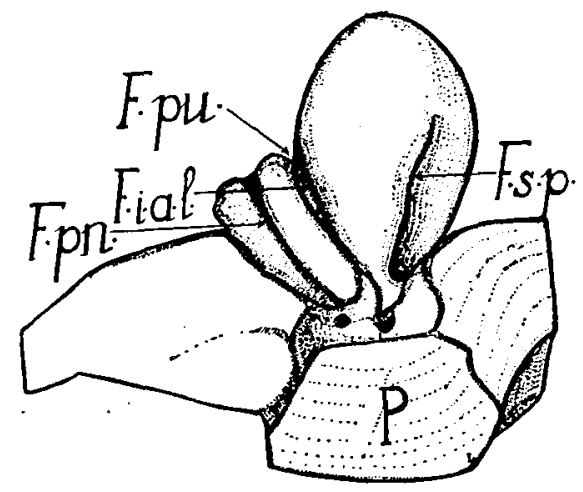

Fig. 9.-Lateral surface of a cerebellum of the end of the third month or of the beginning of the fourth one. Same cerebellum as reproduced in figs. 7 and 8 . F.i.a.l., fissura inferior ant., lateral part; $F \cdot p^{n .,}$ fissura prenodularis; $F \cdot p u$., fissura preuvularis; $F . s p$. , fissura superior post. ; $P$., pons. Enlargement $\times 5$.

The cerebellum I described is remarkable in that it shows a stage in which the central region of the vermis is undivided. This fact seems to plead in favour of the view of Schwalbe [16], Bolk [2], and Ziehen [23], who considered this part of the vermis to form an entity. In the hemisphere it is the later lobuli semilunares superior and inferior, and the lobulus biventer that still constitute an undivided mass.

A somewhat older cerebellum of the first half of the fourth month shows clearly the further subdivision of the central region of the vermis. First, a groove appears, which separates the tuber from the rest of the central part (fig. 10). This groove remains strictly confined to the vermis, but in a later stage of development the fissura horizontalis may unite with it. The remaining undivided part is further split up into two lobules by the median division of the fissura superior posterior. This groove is the last furrow of the vermis to appear. The first vestige of this groove arises at a moment when the lateral division of the furrow reaches the sulcus paramedianus and begins to extend into the vermis (fig. 10). 
The furrowing of the hemispheres also approaches its completion in this stage of development. The grooves to appear last are the lateral division of the fissura inferior posterior and the fissura horizontalis. The

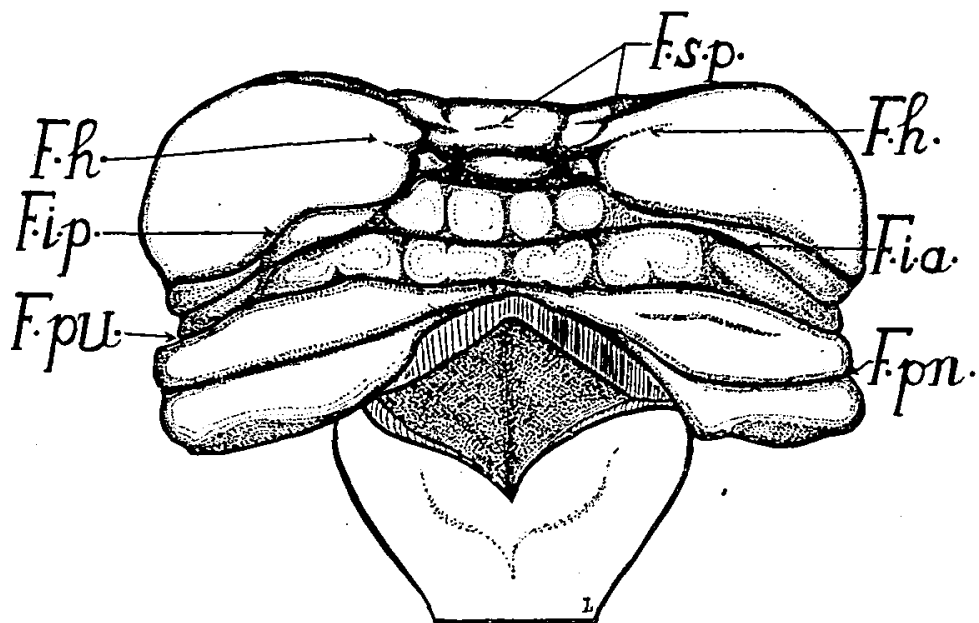

FIG. 10.-Inferior surface of a cerebellum of the first half of the fourth month. F.h., fissura horizontalis ; $F . i . a$, fissura,jinferior ant. ; $F . i . p$., fissura inferior post. ; $F . p n$., fissura prenodularis ; $F^{\prime} \cdot p u$., fissura preuvularis; $F . s . p$., fissura superior post. Enlargement $\times 7$.

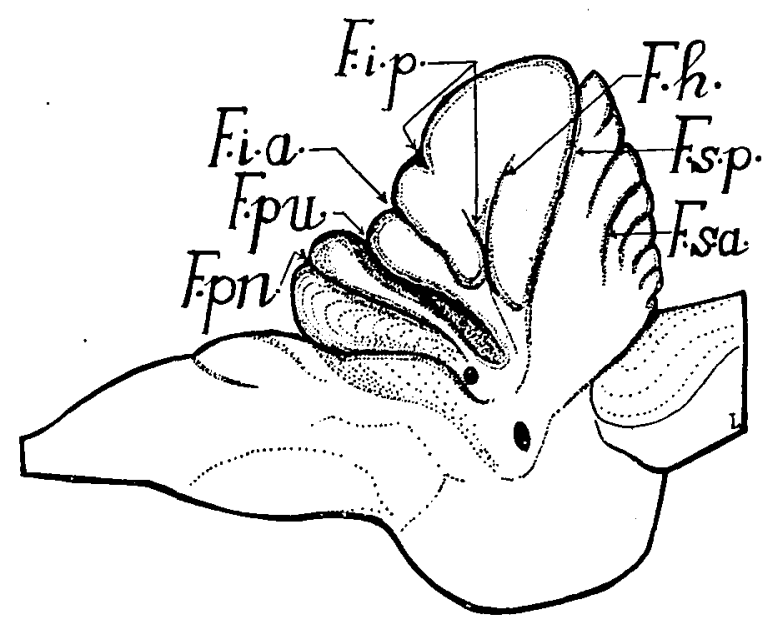

Fig. 11.-Lateral surface of a cerebellum of the first half of the fourth month. Same cerebellum as reproduced in fig. $10 . F . h .$, fissura horizontalis ; $F . i . a .$, fissura inferior ant. ; $F . i . p$. , fissura inferior post. ; $F^{\prime} . m_{\text {. }}$, fissura prenodularis ; $F . p u .$, fissura preuvularis ; $F . s . a$. , fissura superior ant.; F.s.p., fissura superior post. Enlargement $\times 7$.

former usually precedes the latter. The two grooves originate near the lateral margin of the hemisphere (fig. 11). Very soon after the fissura horizontalis has become visible near the lateral margin, a little 
notch appears at the medial side of the hemisphere, which passes into a shallow groove (fig. 10). In the centre of the hemisphere this groove meets that part of the fissura horizontalis which originates near the lateral margin, and unites with it. The fissura horizontalis has, therefore, a double origin in the hemisphere.

The level at which the fissura horizontalis takes its origin on the medial margin of the hemisphere coincides with the groove, which in the vermis separates the folium from the tuber. It is this coincidence which often makes it appear as if the fissura horizontalis were continued into the rermis. That this is not the case and that the fissura horizontalis is merely a hemispherical fissure was recognized by Smith $[17,18]$. The view of Bolk that there is some relationship between the fissura horizontalis and the fissura inferior posterior, or that the fissura horizontalis is simply a branch of the fissura inferior posterior, seems to me erroneous. The fissura horizontalis is the last hemispherical fissure of the human cerebellum to appear; its relation to the fissures of the vermis is rariable, but it is in man a primary fissure of the hemisphere.

In conclusion, therefore, I find that about the middle of the fourth month the fissure formation of the human cerebellum is completed, and that at this period the grooves of the vermis have united with the grooves of the hemispheres. It is by these grooves that the cerebellum is divided into ten lobes, as enumerate $d$ in the table preceding this research. The way in which the cerebellum becomes split up suggests the idea that there is a certain degree of independence of the vermis and of the hemispheres. The formation of fissures, however, takes place according to the same plan and tends to a final state in which vermis and hemispheres appear as parts of an entity of higher order: "the cerebellum." It appears, therefore, likely to me that there may be some truth in the division of the cerebellum by Edinger [7] into a paleo- and a neo-cerebellum. With the details of this division, more particularly with the view that the flocculus appertains to the vermis, I cannot agree.

Before passing on to the description of each of the ten lobes, it is necessary to pay attention to a mode of differentiation of the cerebellar plate, namely, the formation of "foci." A focus is a roundish elevation of the cerebellar surface, of which I do not know at this moment the intimate histological structure. The foci make the impression of being centres of increased growth in the cerebellar surface. The formation of foci is a temporary phenomenon; they first appear at the end of the 
third month, in the vermis behind the fissura superior anterior, and also in front of the fissura preuvularis. Shortly after foci become visible in the adjoining parts of the vermis. Later, the foci disappear and ap to the end of the fourth month the last traces are visible in the uvula and the pyramis. They persist the longest in the pyramis, ${ }^{2}$ where they are also reproduced by Retsius. ${ }^{2}$ Each division of the vermis is built up of four foci, two on each side of the middle line (fig. 10). The medial foci very soon coalesce, forming one large focus, so that in this stage of development every division of the vermis is composed of three foci, one median and two lateral ones (fig. 12).

The formation of foci is not obvious in the hemispheres, except in those parts which adjoin the pyramis and the uvula (figs. 8, 10). In the region adjacent to the pyramis, the formation of a focus is a very transient phenomenon, but the focus lying next to the uvula persists for a long while. This focus makes the impression of being a double focus, and later it develops into the tonsilla.

I choose the cerebellum of the first half of the fourth month as a type for the description of the separate lobes, because at that moment the first phase in the development is terminated with the formation of the ten lobes. The second phase is characterized by the transformation of the lobes into the lobules of the cerebellum.

The cerebellum considered as a whole resembles approximately an ellipsoid body. This form results chiefly from the discrepancy in expansion of the surface and of the stalk, with which the cerebellum is connected to the brainstem. The stalk, which is mainly built up by the brachia, as a result of its intimate constitution, remains behind in expansion as compared with the surface. In consequence of the enormous expansion of the surface, the borders of the cerebellum are rolled inwards. The cerebellum resembles, therefore, in many respects an overfilled, closely tied sack. This rolling inwards of its borders proceeds continuously during the whole course of development and reaches its maximum in the adult stage. Though the rolling inwards of the anterior and posterior borders is most marked, it also happens transversely, and this leads to the formation of the fossa transversa. I received the impression that in the majority of cases the left half of the cerebellum precedes in its morphological differentiation the right half, and that also the rolling inwards is most marked on the left.

1 In the adult form traces of focal differentiation often seem to persist in the lingula. A good specimen of this kind is reproduced by Retsius [14], Table XXXVI, fig. 7 .

2 Retsius [14], Table II, fig. 13, and Table XIV, fig. 2. 
The first lobe is the lobus vinculolingualis. This lobe lies entirely concealed in the depth of the fissura precentralis. In an earlier stage (fig. 7) it is still visible from the outside, but by the increasing rolling inwards of the anterior border it disappears in the depth of the precentral groove. There it forms a small white tongue, which rests upon that part of the tectum mesencephali which later becomes the anterior medullary velum. Laterally, the lingula falls away to the bottom of the groove. These lateral portions of the lingula form the vincula, but a distinct limit between these parts is not yet visible.

The lobus centro-alaris is the second lobe of the cerebellum. This lobe is partly overarched by the lobus culminolunatus, in consequence of the rolling inwards of the border of the cerebellum. The anterior

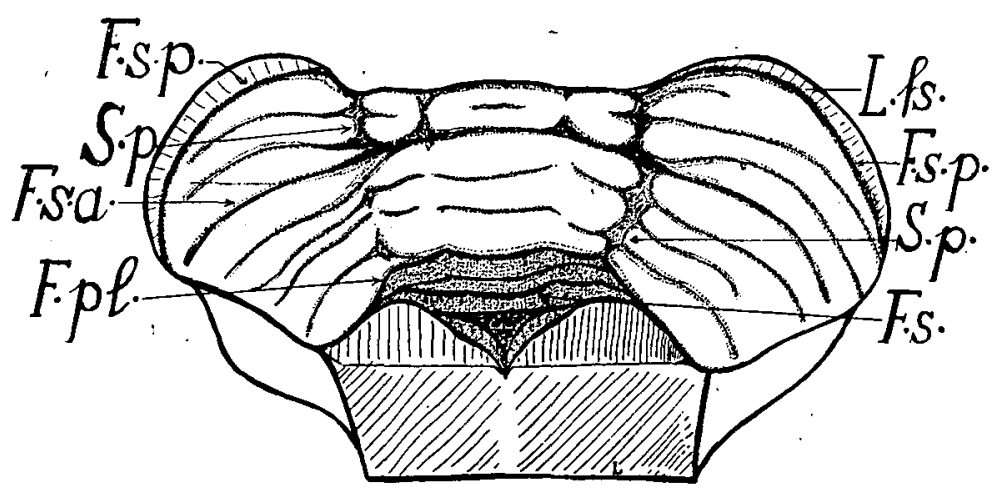

FIG. 12. - Superior surface of a cerebellum of the first balf of the fourth month. Samecerebellum as reproduced in figs. 10 and $11 . F . p l$, fissure prelunata; $F . s$., fissura secundaria ; F.s.a., fissura superior ant.; F.s.p., fissura superior post. ; L.fs., lobus foliosemilunaris.; S.p., sulcus paramedianus. Enlargement $\times 7$.

surface of the lobus centro-alaris rests upon the lingula and the tectum, separated from these structures by the fissura precentralis. The posterior surface rests against the lobus culminolunatus, separated from it by the fissura prelunata. In the stage represented by fig. 12 the last traces of focal differentiation still linger. This enables us to state that the lobulus centralis is the vermis portion of the lobus centro-alaris. The sulcus paramedianus is faintly visible only, forming the limit between the lobulus centralis and the alæ. By a deep secondary groove the lobe is divided into an anterior and a posterior section, of which the posterior section is the larger one. This latter lobule is in its turn subdivided by another secondary groove.

The lobus culminolunatus is the third lobe of the cerebellum. The 
anterior surface of this lobe rests upon the lobulus centralis and the alæ. With its posterior surface the lobe is turned towards the lobus declivolunatus. Here the fissura superior anterior forms the division between the two lobes. The foci are still perceptible and also the sulcus paramedianus, at least in the left half. On the right, this groove begins to disappear. By the sulci paramediani, the lobe is divided into a vermis portion, the culmen, and two hemispherical parts. In a later stáge, when the sulci paramediani have greatly disappeared, the distinction between the vermis and the hemispheres is no longer so evident: Hence, in the adult form this lobe is usually considered to form an entity; the lobulus lunatus anterior (Kölliker). Nevertheless, the discrimination between a vermis portion, the culmen, and a hemispherical section, remains of fundamental interest, independent of the fact that the delimitation between those parts may vanish externally.

If in this stage of development we open the fissura superior anterior, we see at the bottom of this groove lamellæ arising from the posterior surface of the lobus culminolunatus. These lamellæ reach the surface successively, and displace the fissura superior anterior backwards. When this process takes place very actively, it is often difficult, or even impossible, to recognise the original primary fissure. This fact may in a later stage of development cause difficulty in the recognising of the primary fissures, but it is obvious that it does not invalidate the principle of the division of the cerebellum into ten lobes by transversal grooves. The posterior surface of the lobus culminolunatus remains for a long while a centre for the expansion of the cerebellar surface. This process of expansion often proceeds asymmetrically and it also happens that a lamella reaches the surface in the hemisphere, while in the vermis it remains concealed in the depth of the fissure. This is more particularly the case with the lamellæ to be formed last. In fig. 12 an instance of this kind is reproduced on the right.

The fourth lobe in the series is the lobus declivolunatus. The anterior surface of this lobe rests against the lobus culminolunatus, the posterior surface rests against the lobus foliosemilunaris. From this latter lobe it is separated by the fissura superior posterior. This groove extends into the hemisphere as far as the lateral margin (fig. 11). It is the hemispherical boundary groove between the lobali lunati, whilch lie in front, and the lobuli semilunares, which lie behind. The fissura superior anterior, on the contrary, extends only for a short distance into the hemisphere, extending no further laterally than the secondary grooves. The fissura superior anterior may, therefore, $\cdot$ be a groove 
of fundamental interest in the vermis, dividing an anterior from a posterior section (Bradley $[3,4]$, Bolk [2]), but in the hemisphere this rôle falls to the fissura superior posterior. This relation also reflects the temporary independence of the vermis and the hemispheres.

The division into vermis and hemispheres by the sulci paramediani is still very definite in the lobus declivolunatus, and whilst the three foci of the vermis are also obvious. A secondary groove, which is not yet completed, divides the lobe into an anterior and a posterior section. This secondary groove appears first in the hemispheres, and a little later in the central focus of the vermis. During the whole course of its development the lobus declivolunatus is the most conservative part of the cerebellum. Consequently, it forms in the adult stage the part with the simplest configuration. Bolk [2] arrived at a similar result from his studies in comparative anatomy, and proposed the name of lobulus simplex. The close relationship, however, between this and the preceding lobe, especially of the hemispherical section, seems to render it desirable to retain the old name of lobulus lunatus posterior. In connection with the statements and the scheme of Bolk, the fact is worth noticing that the lobus declivolunatus shows clearly in this stage of development the distinction between vermis and hemispheres. Hence the view of this author, that the lobulus simplex would be devoid of a vermis portion, is erroneous.

If we consider the superior surface of the cerebellum as a whole, we are struck by the fact that the vermis forms such a considerable part of it. Later, during the further stages of development, the vermis remains behind in its expansion, and the hemispheres become more and more predominant.

The fifth lobe is the lobus foliosemilunaris. This lobe borders from behind on the fissura horizontalis. In the specimen reproduced in figs. 10 and 11, this fissure is not yet completed, but in other objects of approximately the same age the furrow is completed. Hence I cannot agree with Smith [19], who believes that it is not until the end of the fifth or the beginning of the sixth month that the 'fissura horizontalis makes its appearance.

The vermis part of the fifth lobe, the folium, in this stage of development still forms.an element of the external surface. Later, however, it gradually remains behind and is in many cases overgrown by the adjacent parts, and especially by the lamellæ of the tuber. The folium is the last differentiated section of the vermis and, in the adult stage, the most reduced one. It is, like the other sections of the vermis, 
originally built up of four foci, but the focal differentiation appears! to be transient and to disappear early. Slight displacements may occur in this region between the folium and the adjacent parts of the hemispheres, caused by difference in the rates of expansion of the surface. In consequence of these displacements the endings of the fissura horizontalis and the furrow that separates the folium from the tuber no longer coincide. In this way the different varieties arise, which are met with in the adult in this region. The region of the folium is last differentiated and for this reason it is the most variable part of the human cerebellum.

The hemispherical section of the lobus foliosemilunaris, the lobulus semilunaris superior, is not yet split up by secondary grooves. These grooves appear comparatively late, not before the middle or the end of the fifth month.

The lobus tuberosemilunaris is the sixth lobe. It is separated from the lobus pyramidobiventricus by the fissura inferior posterior. The vermis section of the lobe is subdivided into three parts. The median part, which is by far the largest, takes its origin from the central: focus. Later, it develops into the tuber. Both the lateral parts are derived from the lateral foci. These parts remain behind in development, but until the middle of the fourth month they are distinctly separatea elements of the vermis. In a later stage, these little fields disappear in the depth of the fissura inferior posterior and there form the small white stalks that unite the tuber with the foremost lamellæ of the lobulus semilunaris inferior. The tuber differs, therefore, in so far from the other lobules of the vermis that it takes its origin only from the central focus.

The two lobuli semilunares give the impression of forming an entity, which is at a comparatively late stage subdivided by the fissura horizontalis. The surface expansion of the lobuli semilunares begins at a very early stage and is most definite in the inferior lobule.: In consequence of the considerable development of these lobules, the lateral division of the fissura inferior posterior no longer runs transversally, but bends off a little backwards. In later stages, when the lobuli semilunares prevail still more, the backward inclination of the furrow becomes more accentuated. The excessive expansion: of the lobuli semilunares dominates the whole development of the cerebellum, and produces, together with the enormous development, of the tonsillæ; , the anomalous appearance of the human cerebellum.

si.

The seventh lobe is the lobus pyramidobiventricus, This is 
separated from the preceding one by the fissura inferior posterior, and from the lobus uvulatonsillaris by the fissura inferior anterior. The vermis section of this lobe is strongly developed, and still shows in the stage represented in fig. 10 four foci. In another object of approximately the same age the medial foci partly coalesce. The focal differentiation is sharply marked in the pyramis, and it is here that the foci persist longest. The hemispherical part of the lobe, the later lobulus biventer, is narrow, in consequence of the compression exerted by the posterior border of the lobulus semilunaris. Towards the lateral margin of the hemisphere, the lobule grows broader and its surface more convex, so that it appears there as a well-marked part of the lateral surface of the cerebellum (fig. 11).

The hemispherical region immediately adjoining the vermis gives the impression of being differentiated into a focus (fig. 10, on the left). The oblong form of this focus appears to be caused by the compression brought to bear by the posterior border of the lobulus semilunaris, for in an earlier stage this focus is more rounded (fig. 8). In a later stage of development, this focus is overgrown by the adjacent parts of the hemisphere and lies at the bottom of the fissura inferior anterior. There it develops into the white stalk, by which the pyramis is united with the lamellæ of the lobulus biventer. Between the hemispherical focus and the lateral focus of the vermis lies a slightly depressed triangular field, with its base turned towards the fissura inferior anterior. This little field, which is of considerable size when the hemispherical focus is reduced (fig. 10, on right), gives origin, so far as I can see, to the area perforata parapyramidalis of Ziehen [23]. The rest of the hemispherical part of the lobus pyramidobiventricus shows no trace of focal differentiation.

The lobus uvulatonsillaris is the eighth lobe. This lobe is limited by the fissura inferior anterior on one side, and by the fissura preuvularis on the other. This latter groove is a fairly deep furrow, which near the lateral border of the hemisphere grows broad and shallow (fig. 11). In its general features this lobe resembles the preceding one. The vermis part, which still shows four distinct foci, develops into the uvula. The hemispherical part of the lobe is compressed by the lobulus semilunaris, in the same way as the lateral division of the lobus pyramidobiventricus. The region of the hemisphere adjacent to the uvula is focally differentiated. The focus gives the impression of being double; later, it develops into the tonsilla. In the human cerebellum, therefore, the uvula and the tonsilla are originally contiguous parts, belonging to 
the same lobe and only separated from each other by the sulcus paramedianus. For this reason I cannot agree with Smith [19], who believes that the connexion between uvula and tonsilla is a secondary one only.

The next lobe, the ninth, is the lobus nodulofloccularis. This is separated from the tenth by the fissura prenodularis. In the stage represented by figs. 10 and 11 it is a well-developed lobe, but very soon it remains behind in development, especially the more medial part of the hemispherical section.

The more lateral part of the hemispherical section differentiates further and gives rise to the flocculus. In consequence of the rolling inwards of the posterior border of the cerebellum, the vermis and the parts adjacent to it are turned towards the fourth ventricle. Hence, the greater part of the nodulus is no longer directly visible. The focal differentiation of the nodulus is only faintly indicated, but the lines of demarcation formed on the sides by the sulci paramediani are clearly defined.

The last lobe is the lobus nodiolovelaris. This lobe had already been recognised by Kölliker [10] as a separate division of the cerebellum, to which he applied the term of "gyrus chorioideus posterior." It is a well-developed lobe, of which the vermis and the adjacent parts of the hemispheres are entirely reversed. From behind, this lobe is continued into the posterior medullary velum. The transition of the velum into the substance of the lobe lies in the central region, not on the posterior border, but a little to the front, so that. the nodiolus and the adjoining parts of the hemisphere are covered by the velum.

The nodiolus forms the hindmost section of the nodulus, from which it is separated by the median part of the fissura prenodularis. On the side, the nodiolus is delimited by the sulci paramediani. The wall of the hemispherical section of the lobe atrophies for a great deal in the - course of development and is assimilated to the velum. For that reason, I choose the name of lobus nodiolovelaris for this last lobe of the cerebellum.

The next stage is derived from an embryo of the end of the fourth month. At that time the focal differentiation of the superior surface has entirely disappeared and only the last traces of the sulci paramediani are visible (fig 13). The hemispheres have considerably increased their surface and embrace the brainstem. By the change in the form of the superior surface, the course of the fissures is altered. Instead of running transversely they now curve forwards in the hemispheres in agreement with the form of the cerebellum. 
The lingula is still small and concealed in the depth of the fissura precentralis. The central lobe forms at this stage the bottom of a niche, enclosed from the side and above by the lobus culminolunatus. This lobe assumes more and more the form of a crescent. By the disappearance of the sulci paramediani, the limit between the vermis and the hemispheres vanishes, and from that moment the lobe gives the impression of being an entity, the lobulus lunatus anterior of descriptive anatomy. In the same way the lobus declivolunatus is transformed into the lobus lunatus posterior. This lobe shows on the right the formation of a secondary groove in the substance of the hemisphere, independent of the existing grooves. At the bottom of this secondary groove lamellæ are formed, which later emerge on the surface.

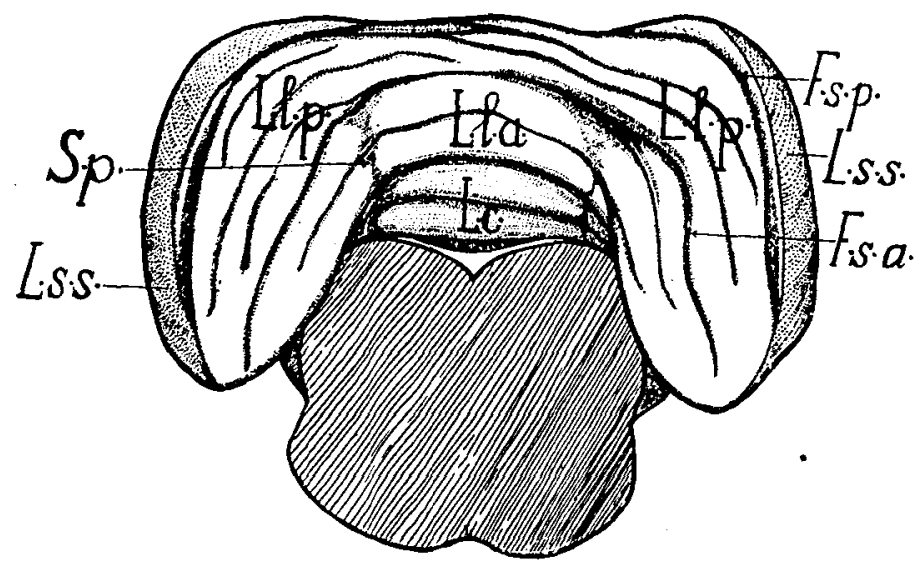

Fig. 13. - Superior surface of a cerebellum of the end of the fourth month. F.s.a., fissura superior ant. ; F'.s.p., fissura superior post. ; L.c., lobulus centralis; L.l.a., lobulus lunatus ant. ; L.l.p. lobulus lunatus post.; L.s.s., lobulus semilunaris superior; S.p., sulcus paramedianus. Enlargement $\times 5$.

The lobulus lunatus posterior is limited from behind by the fissura. superior posterior. This fissure forms a deep groove, which near the lateral margin of the hemisphere flattens and passes over into that part of the fissura precentralis that separates the hemispheres from the brainstem (fig. 15). In this manner a part of the forelip is formed of the fissura transversa.

The inferior surface of the cerebellum seems in many respects more conservative than the superior one. The chief changes are caused by the increase of the lobulus semilunaris. By the great increase in size of this lobe, the lobulus semilunaris superior begins to embrace the 
lobulus lunatus posterior from aside (fig. 13). In this way the lobulus semilunaris superior reaches the upper surface, of which it now forms the lateral border. Consequently, the fissura superior posterior is displaced forwards and ceases to be the limit between the superior and the inferior surfaces. This process gradually proceeds in the same direction, until in the course of the sixth month approximately the whole lobulus semilunaris superior forms part of the upper surface. At that moment the fissura horizontalis becomes the limit between the superior and the inferior surfaces of the cerebellum. The displacement of the fissura superior posterior is often overlooked and it was Stroud [22] and Bolk [2] who clearly recognized this fact.

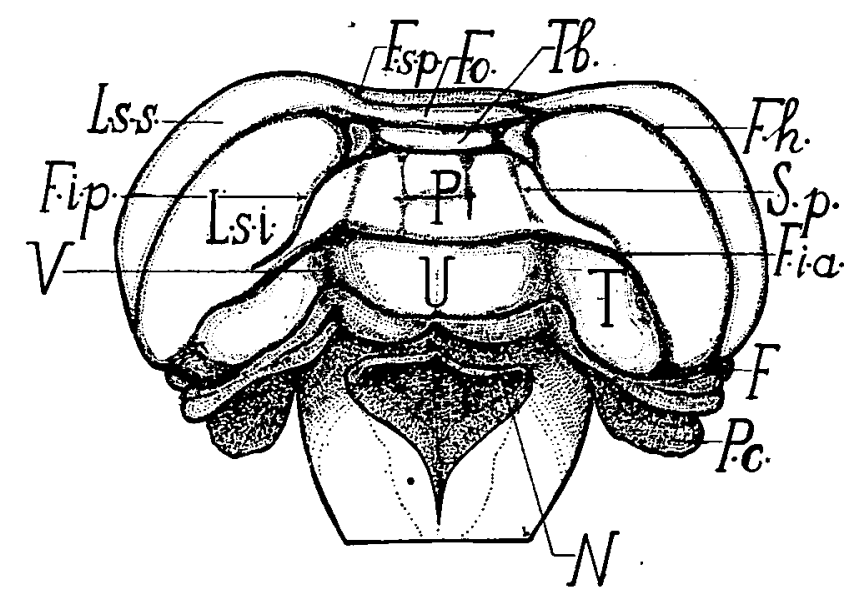

Fig. 14.-Inferior surface of a cerebellum of the end of the fourth month. Same cerebellum as reproduced in fig. 13 . F'., flocculus; $F . h$., fissura horizontalis ; $F . i . a$. , fissura inferior ant ; F.i.p., fissura inferior post. ; Fo., folium ; $F . s . p$. , fissura superior post. ; $L . s . i$. , lobulus semilunaris inferior ; L.s.s., lobulus semilunaris superior ; $N$., nodulus; $P$.. pyramis ; $P . c .$, plexus chorioideus; S.p., sulcus paramedianus ; $T$., tonsilla; $T b$., tuber ; $\ddot{U}$., uvula ; $V$. vallecula. Enlargement $\times 5$.

The lobulus semilunaris inferior still further increases in size and compresses more and more the lateral division of the lobus pyramidobiventricus. The fissura inferior posterior approaches thereby the fissura inferior anterior, while at the same time the more lateral part of the groove becomes flattened and disappears (fig. 14). Finally, in a somewhat older stage than that reproduced in fig. 14, the fissura inferior posterior may unite with the fissura inferior anterior. This state is nearly attained on the right side of fig. 14. By the disappearance of the fissura inferior posterior, the impression is conveyed that the lateral 
part of the lobus pyramidobiventricus, i.e., the lobulus biventer, has vanished. Later, however, the fissura inferior posterior reappears (cf. fig. 18). As far as I can see, the disappearance of the more lateral part of the fissura inferior posterior is a normal phenomenon, which always occurs in this stage of development. The union, however, of this fissure with the fissura inferior anterior seems not so constant and in that respect there may even be differences between the right and the left half of the same cerebellum.

The folium, which joins together the two lobuli semilunares superiores, begins to remain behind in its development and in some specimens of approximately the same age it already lies a little below the level of the adjacent parts of the vermis. The tuber, on the contrary, has greatly increased in size, especially in a transverse direction. The small flat fields beside the tuber, which derive from the lateral foci of the vermis, are partly overgrown and begin to disappear from the surface. Later, they form the little white stalks that unite the tuber with the lobuli semilunares inferiores.

In the pyramis the last traces of focal differentiation persist, and this makes it possible to state that the little field, limited laterally by the rest of the fissura inferior posterior, is chiefly composed by the hemispherical focus. The pyramis and the hemispherical foci still lie on the same level, but later the hemispherical foci disappear in the depth of the fissura inferior anterior, where they form the white stalks that unite the pyramis with the lobuli biventeres. In the case of the pyramis it is quite evident that the white stalks derive from the hemispherical foci and one would expect this to be also the case with the stalks uniting tuber and lobulus semilunaris. As far as my material goes, however, the stalks of the tuber seem to proceed from the lateral foci of the vermis.

The lobus uvulatonsillaris is at this stage of development no more a transverse lamella. In consequence of the expansion of the lobulus semilunaris, the tonsilla is displaced and the rest of the hemispherical division of the lobe strongly compressed. The tonsilla now forms an obtuse angle with the uvula and the region between these structures is depressed (fig. 14). This depressed area forms the first origin of the valecula, and because the sulcus paramedianus lies at the bottom of the depression we may say that the valecula arises in the situation of that sulcus. Under the influence of the compression exerted by the lobulus semilunaris inferior, the more lateral part of the hemispherical division of the lobus uvulatonsillaris atrophies, with the exception of a little 
well-marked field adjoining the margin of the hemisphere in front of the flocculus (fig. 15). This little field is variable in form and size in different specimens, but it always persists as a distinctly limited and slightly convex area till the sixth or seventh month, or perhaps still longer. This little field, which arises from the most lateral part of the hemispherical division of the lobus uvulatonsillaris, is in my opinion the homologue of the paraflocculus of Smith, the ventral part of the paraflocculus of Bradley and the pars tonsillaris of the formatio vermicularis of Bolk.

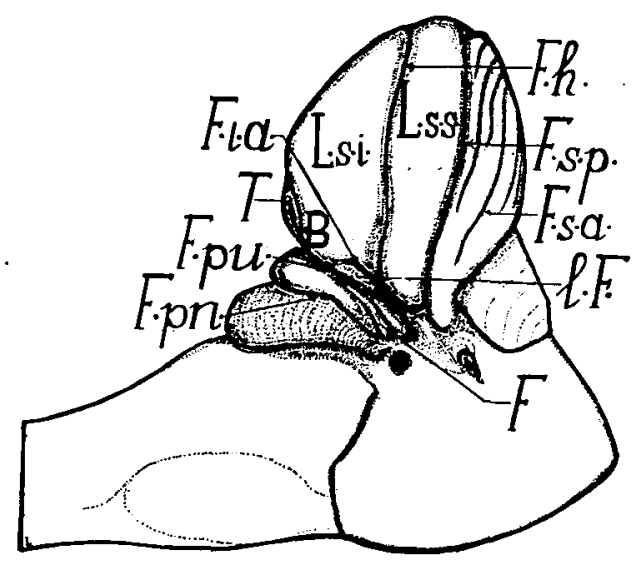

Frg. 15. - Lateral surface of a cerebellum of the end of the fourth month. Same cerebellum as reproduced in figs. 13 and 14 . $B$., lobulus biventer; $F$., flocculus ; $F . h$., fissura horizontalis; $\vec{F} . i . a$. , fissura inferior ant.; $F . p n$., fissura prenodularis; $F . p u .$, fissura preuvularis; $F$.s.a., fissura superior ant.; $F$.s.p., fissura superior post. ; l. $F$., lateral field ; L.s.i., lobulus semilunaris inferior; L.s.s., lobulus semilunaris superior; $T$., tonsilla. Enlargement $\times 5$.

The fissura inferior anterior, which forms the front border of the lobus uvulatonsiliaris, is in its vermis portion a fairly deep groove. In the hemisphere the groove flattens in the neighbourhood of the lateral pole of the tonsilla. Near the margin of the hemisphere, where it forms the anterior limit of the little lateral field, the groove is again well defined.

The lobus nodulofloccularis has to a great extent disappeared from the surface by the rolling inwards of the posterior border of the cerebellum. Only a small strip is visible, which is partly overarched by the posterior border of the lobus uvulatonsillaris. From this lobe it is separated by the fissura preuvularis. This groove is deep in the vermis, flattens in the hemisphere, in consequence of the incipient atrophy of the wall of the lobe, and again grows deeper near the lateral 
margin of the hemisphere; there it borders the flocculus in front. The fissura prenodularis forms the posterior limit of the lobe. This groove is well marked, though not very deep in the hemisphere.

The lobus nodulofloccularis can only be exposed to view by rolling the posterior border of the cerebellum outwards. This I have done in a somewhat older specimen. The embryo from which this cerebellum came was about four months old, or perhaps slightly older. Fig. 16 is the reproduction of the preparation. The vermis part is well developed and laterally bordered by the last traces of the sulci paramediani. The lobe is divided by a secondary groove into an anterior and a posterior division. The first trace of this groove is represented in fig. 10, on the right, and in the stage of fig. 14 the groove approaches its completion. Later, the hemispherical division of the groove disappears in consequence of the atrophy of this part of the lobe.

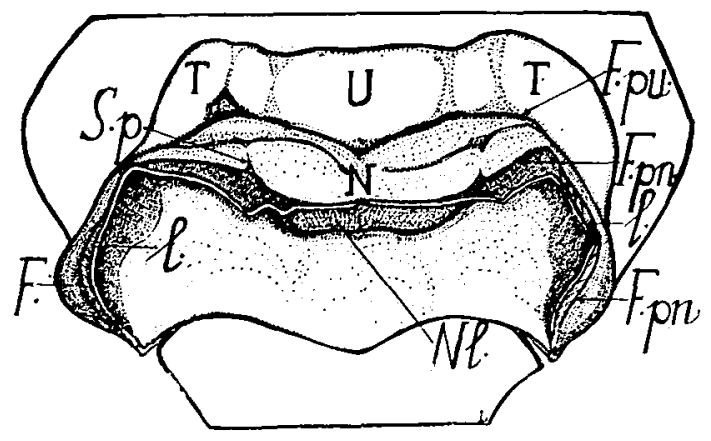

FIG 16.--Posterior border of a cerebellum of an embryo of about four months old. $F$., flocculus ; $F^{\prime} \cdot p \imath$., fissura prenodularis; $F \cdot p u$., fissura preuvularis ; $l$., line along which the medullary velum is torn off; $N$., nodulus; N.l., nodiolus ; S.p., sulcus paramedianus ; $T$., tonsilla; $U$., uvula. Enlargement $\times 5$.

The most lateral part, however, of the lobus nodulofloccularis does not share the atrophy of the rest of the hemispherical division, but develops into the flocculus. In the stage represented in fig. 11, this part of the lobe is only a narrow band, bordered in front by the shallow extremity of the fissura preuvularis. Gradually this part increases in size and forms a club-like lobule, by which the shallow groove is partly filled up. The continuation of the secondary groove extends into this lobule and divides the head of the club into two parts. Very early a short lamella is formed in the depth of the fissura preuvularis, emanating from the anterior surface of the flocculus. This lamella soon reaches the surface and from that moment the flocculus is composed of three 
short lamellæ, which are continued medially into a broad white stalk. This stalk gradually thins off in consequence of the proceeding atrophy of the middle division of the hemispherical part of the lobe. By the atrophy of this part of the lobe, the fissura preuvularis and prenodularis vanish, with the exception of those parts that limit the flocculus. Medially from the flocculus and in the neighbourhood of the lateral pole of the tonsilla, the two grooves often become confluent and may join the fissura inferior anterior, which also begins to flatten in this region. The atrophied part of the lobe is assimilated to the medullary velum and at that moment the stalk of the flocculus seems to arise in the velum. The degree reached by the atrophy of the lobus nodulofloccularis varies in different specimens, and it is this variability that explains the differences in the form and the relations of the flocculus and its stalk to the surrounding parts in the adult.

The lobus nodiolovelaris increases in size, especially the hemisperical division; this is accompanied by a progressive atrophy of the wall of the lobe, which is gradually transformed into the plexus chorioideus. In the preparation reproduced in fig. 16, I roughly removed the plexus and the atrophied part of the velum. What remains of the lobe is the non-atrophied part. The line along which the plexus and the velum are torn off runs over the external surface of the vermis approaching the fissura prenodularis (fig. 16). In a later stage this line reaches the fissura prenodularis at the lateral border of the vermis. and is there continued along the bottom of the groove. The transition of the cerebellar plate into the velum lies, therefore, in the region of the vermis, not at the posterior margin of the plate, but a little more to the anterior, as already described. Hence the statement of Ziehen [23] that in the adult stage the nodiolus lies intra-velar, covered by the two sheets of the velum, seems erroneous to me, for the velum at the place of transition does not form a duplicature, nor is the velum built up by two distinct sheets.

In the beginning and also during the first half of the fifth month, the further expansion and development of the lobulus semilunaris is the dominating fact. This lobule, considered as a whole, becomes more convex and more distinctly marked off, especially along its lateral border. In the meantime, the lateral division of the fissura inferior posterior reappears. The first trace of the groove emanates from the still existing branch, but very soon the groove arises, also in the middle of the hemisphere, extending towards the lateral border (fig. 17). At the end of the fifth month or the beginning of the sixth, the groove is 
completed [figs. 18 and 19]. With the reappearance of the fissure, the lobulus biventer is again split off from the lobulus semilunaris inferior. Hence by the reconstruction of the fissura inferior posterior the original state is restored.

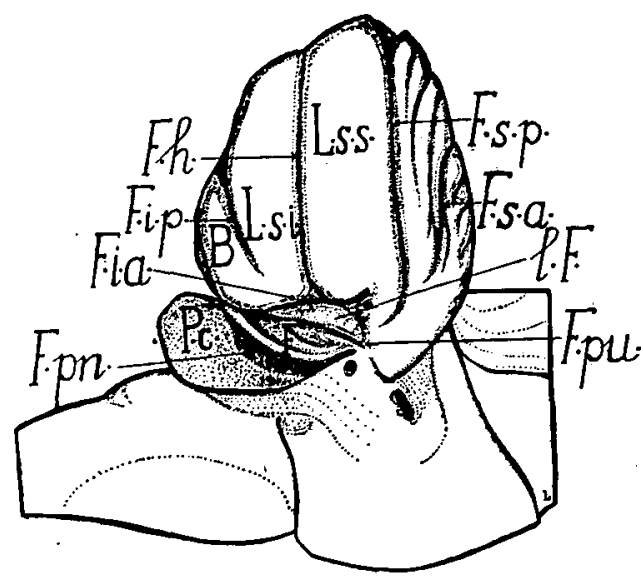

EIg. 17.-Lateral surface of a cerebellum of the first half of the fifth month. B., lobulus biventer; $F$., flocculus ; $F . h$., fissura horizontalis; $F . i . a$. , fissura inferior ant.; $F . i . p$. , fissura inferior post.; $F . p m$., fissura prenodularis ; $F . p u$., fissura preuvularis; $F . s . a$. , fissura superior ant. ; F.s.p., fissura superior post. ; l.F., lateral field ; L.s.i., lobulus semilunaris inferior; I.s.s., lobulus semilunaris superior; P.c., plexus chorioideus. Enlargement $\times 5$.

In consequence of the compression exerted by the expanding lobulus semilunaris, the lateral field belonging to the lobulus uvalatonsillaris has lost its connexion with the rest of the lobe. Laterally from the tonsilla, the fissura inferior anterior has joined the fissura preuvularis as represented in fig. 18, on the left. On the right there still exists a small strip uniting the tonsilla with the lateral field. The little field itself may further increase in size, but very soon lags behind and slowly disappears as a separate field.

The atrophy of the lobus nodulofloccularis proceeds further during the first half of the fifth month, and the hindmost lamella of the flocculus shares the regression of the lobe. The two other lamellæ, on the contrary, increase in size, so as to give the impression as if the flocculus were composed by only two lamellæ.

The next stage belongs to an embryo at the end of the fifth month. The changes in the superior surface are not very considerable. This part of the cerebellum continues to develop in the same direction as that already described. The rolling inwards of the anterior border has a 
little advanced, and the arching of the middle region, the vermis of descriptive anatomy, is also more evident.

On the inferior surface the regression of the folium and the further development of the tuber and the pyramis are the most striking features (fig. 18). The little fields between the tuber and the lobulus semilunaris inferior have disappeared from the surface. They begin to assume the form of narrow white bridges uniting the tuber with the lobulus semilunaris. The pyramis has strongly increased in size and shows a new set of secondary grooves. In this specimen the last traces of focal differentiation persist in the pyramis, but in most specimens of

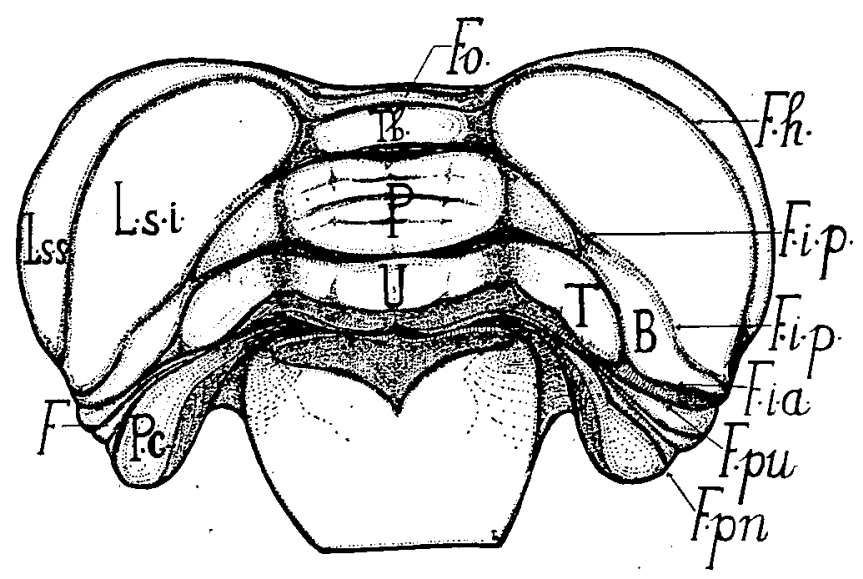

Fig. 18. - Inferior surface of a cerebelium of the end of the fifth month. B., lobulus biventer; $F$., flocculus ; $F . h$., fissura horizontalis ; $F . i . a$. , fissura inferior ant. ; $F . i . p$. , fissura inferior post; Fo., folium; $F \cdot p n$., fissura prenodularis ; $F . p u$., fissura preuvularis ; L.s.i., lobulus semilunaris inferior ; L.s.s., lobulus semilunaris superior ; P., pyramis ; P.c., plexus chorioideus; $T$., tonsilla ; Tb., tuber ; U., uvula. Ealargement $\times 5$.

the same age the focal differentiation has already entirely disappeared. It seems evident in this specimen that the transverse dimension of the tuber agrees with the dimension of the median focus of the pyramis, so that this also speaks in favour of the view that the tuber is the derivative of the median focus only.

The hemispherical foci of the lobus pyramidobiventricus have developed into well limited triangular fields, which form the union between the pyramis and the lobulus biventer. They still lie on the surface of the cerebellum, but by the formation of the vallecula they disappear from the surface, forming an element of the bottom of this depression. There they persist, even in the adult stage, as the white stalks uniting the pyramis with the lobulus biventer, and as the little 
fields described by Ziehen as the "areæ perforatæ para-pyramidales." By the reconstruction of the fissura inferior posterior the lobulus biventer reappears as a separate lobe, which in this specimen extends as far as the lateral border of the hemisphere.

The lobulus uvulatonsillaris has remained behind in its development, in comparison with the preceding lobes. It is only in a later period that the tonsillæ, independently of the uvula, begin to expand and to increase in size. The uvula shows now the first secondary groove, but often this groove is not visible from the outside, in consequence of the rolling inwards of the posterior border. By the same process the lobus nodulofloccularis disappears more and more from the inferior surface. Meantime this lobe partly atrophies, and it is only the nodulus and the two foremost lamellæ of the flocculus that become further differentiated. The wall of the posterior lamella of the flocculus atrophies and the fissura prenodularis, in as far as it limits the flocculus from behind, flattens and vanishes. The atrophy of the lamella and the disappearance of the fissure usually begin at the lateral margin of the hemisphere and proceed medially. By this process the posterior lamella of the flocculus is assimilated to the velum and the fissure that now separates the flocculus from the velum is no longer the lateral extremity of the fissura prenodularis, but the secondary groove, which initially divided the head of the flocculus into two lamellæ. At the same time, however, one or two small lamellæ are formed, emanating from the anterior surface of the flocculus. These lamellæ at the moment of their formation are concealed in the depth of the fissura preuvularis, but later one of these lamellæ may reach the surface.

The lobus nodiolovelaris also atrophies for the greater part, with the exception of those portions which form the nodiolus and the chorioid plexus. The atrophied parts of the lobe are also incorporated in the medullary velum.

In fig. $19 \mathrm{I}$ reproduce the lateral aspect of the same cerebellum from the right side, because it exhibits many peculiarities. It shows the connexion between the uvulatonsilla and the lateral field belonging to this lobe. The lateral field itself is well marked and fairly large. In front this field is limited by a relatively deep groove, the lateral extremity of the fissura inferior anterior. In front of the fissura inferior anterior another groove is visible, which becomes flattened, and seems to end in the neighbourhood of the lateral margin of the hemisphere. This groove is the lateral extremity of the fissura inferior posterior, which borders in front the lobulus biventer. The small strip 
of substance between this latter groove and the fissura inferior anterior belongs, therefore, to the lobulus biventer, with which it is still in continuity. This fact proves that by the reappearance of the groove that borders in front the lobulus biventer, the original state is in reality restored. In most cases, however, this lateral part of the fissura inferior posterior does not reappear, and the groove ends at some distance from the lateral border of the hemisphere.

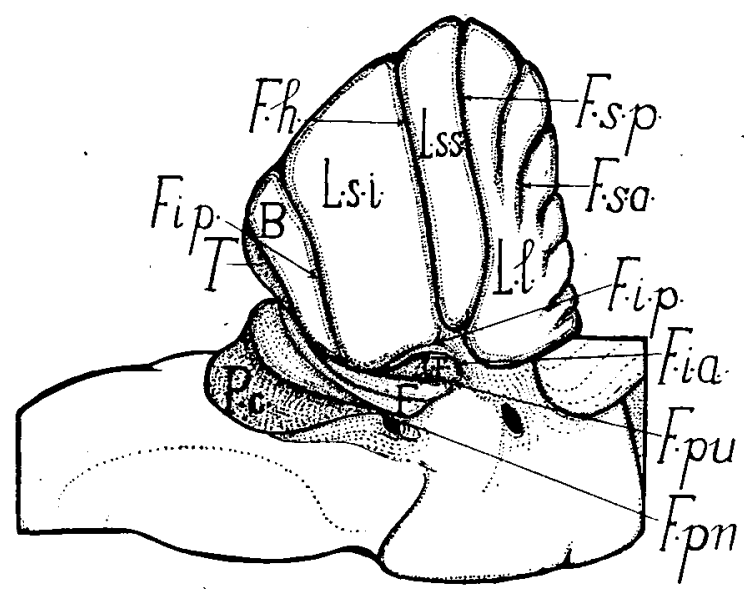

Fig. 19.-Lateral surface of a cerebellum of the end of the fifth month. Same cerebellum as reproduced in fig. 18 . $B$., lobulus biventer; $F$., flocculus; $F . h$., fissura borizontalis; $F . i . a$. , fissura inferior ant. ; $F . i . p$. , fissura inferior post; $F \cdot p n$., fissura prenodularis ; $F \cdot p u$., fissura preuvularis ; $F$ 's.a., fissura superior ant. : $F$.s.p., fissura superior post. ; l. $F$., lateral field ; L.l., lobulus lunatus; $L . s . i .$, lobulus semilunaris inferior; $L$.s.s., lobulus semilunaris superior; P.c., plexus chorioideus; T., tonsilla. Enlargement $\times 5$.

In this specimen the fossa transversa makes its appearance as a little depression bordered anteriorly by the lobuli lunati and the lobulus semilunaris superior. The appearance of the fossa transversa indicates the beginning of the third phase in the development of the human cerebellum. It coincides approximately with the end of the fifth or the beginning of the sixth month. The chief characteristic of this third phase resides in the enormous expansion of the hemispheres. The enlargement of the surface, however, is not uniform throughout, but some parts increase, while others decrease or disappear. By this process of local differentiation the cerebellum approaches the adult form.

The expansion of the surface begins near the lateral border of the hemisphere, and is accompanied by a temporary flattening and disappearance of the grooves. There seems to exist a certain antagonism between furrowing and expansion, for, as soon as the expansion becomes 
less intense, the grooves reappear. The reconstruction of the furrows occurs, partly autonomously, partly by the outgrowth of the still existing branch of the groove. Most grooves, however, are not 'completely reconstructed, so that in the adult stage they no longer reach the lateral edge of the hemisphere. In such cases one gets the impression that the hemisphere winds like a gyrus round the end of the sulcus. This fact has probably led Bolk to the conception of a "lobulus ansiformis"; but it is evident that this conception has no fundamental importance, and can only lead to confusion.

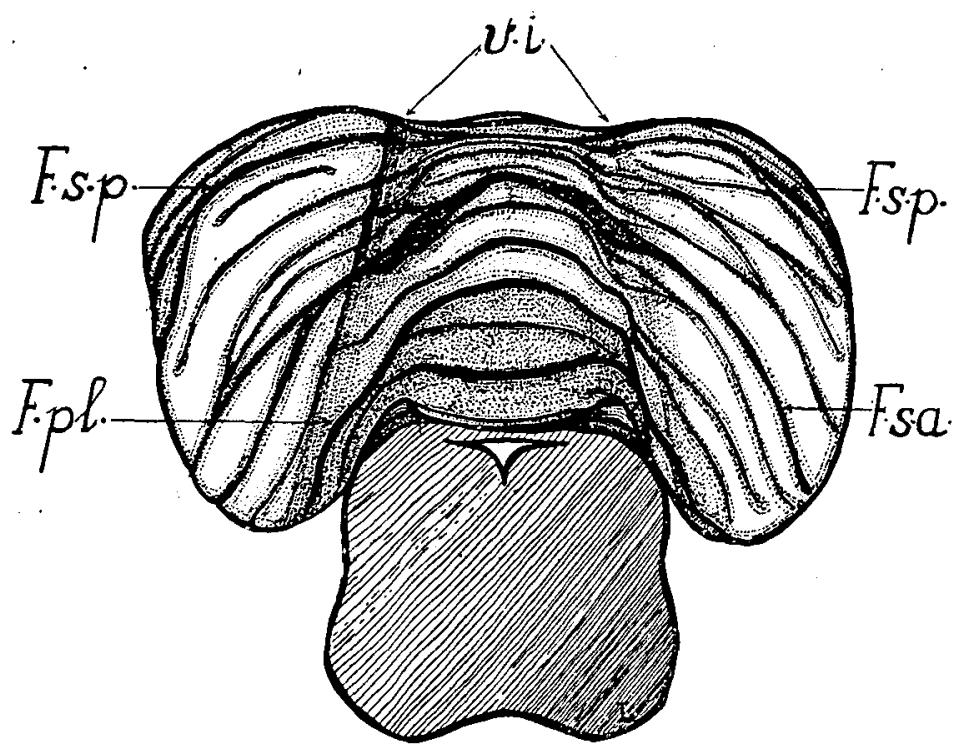

Fig. 20.-Superior surface of a cerebellum of the beginning or of the middle of the sixth month. $F^{\prime} . p l$., fissura prelunata: $F^{\prime} . s . a$. , fissura superior ant. ; $F . s . p$. , fissura superior post. : v.i, vascular impression. Enlargement $\times 4$.

The development of the superior surface of the cerebellum during the last phase is a mere continuation of the processes already mentioned. The vermis becomes more arched, but remains behind in its expansion in comparison with the hemispheres. The hemispheres become, therefore, the predominant parts of the cerebellum. There is no longer a distinct limit between the vermis and the hemispheres. In fig. $20 \mathrm{I}$ reproduce the superior surface of a cerebellum of the beginning, or, perhaps, middle of the sixth month, to illustrate these relations. On both sides of the vermis a longitudinal impression is seen produced by the blood-vessels; but it is obvious that this impression cannot be taken as a limit between vermis and hemispheres. 
The lingula at this stage of development has attained its definitive form, the alæ being separated from the middle division by a faint longitudinal groove. This groove is the last remainder of the sulcus paramedianus (fig. 21). The whole formation lies concealed in the depth of the fissura precentralis, covered by the lobulus centralis.

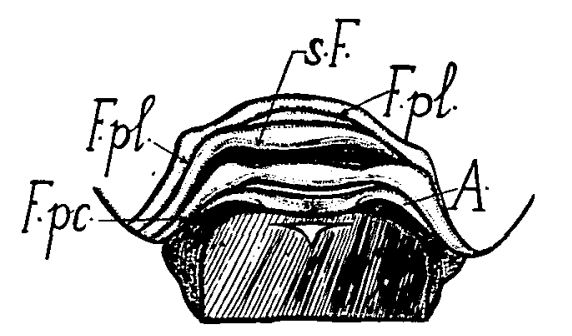

FIG. 21.-Anterior border of a cerebellum of the sixth month. Same cerebellum as reproduced in fig. 20 . A., ala lingulæ; $F$.pc., fissura precentralis; $\dot{F}$.pl., fissura prelunata; s. $F$., deep secondary furrow, dividing the lobulus centralis into two sublobules. Enlargement $\times 5$.

The lobulus centralis is divided by a deep secondary groove into two sublobules. The foremost of the these sublobules has partly disappeared from the surface by the rolling inwards of the anterior border of the cerebellum (fig. 20). The hindmost sublobule, which is the larger one, is still visible, being only partly covered by the lobulus lunatus. Each of the two sublobules is again split up by a secondary groove, so that the whole lobulus centralis is composed of four sublobules. The fissura prelunata, which borders the lobulns centralis from behind, lies in this specimen still entirely in the superior surface, though, on the left, in consequence of the proceeding inward rolling of the anterior border, the furrow begins to disappear from the surface. In other specimina of approximately the same age the rolling inwards of the anterior border has further advanced, so that the lateral division of the fissura prelunata is no more visible. In this respect they more closely resemble the adult form.

A specimen of this kind is reproduced in fig. 22, as seen from the side. The cerebellum belongs to an embryo of the beginning of the sixth month. In this case the lobulus lunatus forms already a niche, in which the lobulus centralis is imbedded. In fig. 23 I reproduce a slightly older stage, in which the development of the lobulus lunatus has further advanced, and in which the covering of the lobulus centralis is more complete. The formation of the niche is the joint result of the 
rolling inwards of the anterior border and of the surface expansion of the lobulus lunatus.

The fissura superior anterior, which divides the lobulus lunatus into an anterior and a posterior division, is no longer the leading groove of the superior surface. For the formation of new lamellæ in the depth of the groove is no longer so active, and those that are formed do not reach the surface. In the lobulus lunatus posterior small lamellæ are formed, which unite the existing ones. The grooves, by which these small cross-lamellæ are bordered, form the "sulci pectinati obliqui " of Ziehen [23].

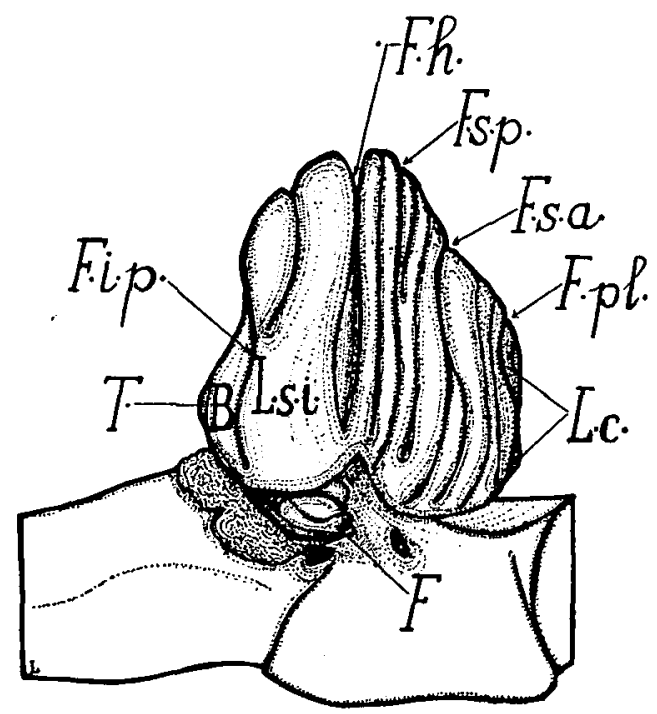

Fig. 22.-Lateral surface of a cerebellum of the beginning of the sixth month. $B$, lobulus bivenier; $F$, flocculus ; $F . h$, fissura horizontalis; $F^{\prime} . i . p$., fissura inferior post. ; $F . p l$., fissura prelunata; $F . s . a$. , fissura superior ant.; $F . s . p .$, fissura superior post. ; L.c., lobulus centralis; L.s.i., lobulus similunaris inferior; T., tonsilla. Enlargement $\times \dot{4}$.

At this stage the fissura superior posterior, which limits the lobulus lunatus from behind, lies entirely in the superior surface. Laterally, where the groove approaches the lateral border of the hemsiphere, it is widened out (fig. 23). At the bottom of this little excavation, a small lamella is formed. This lamella, which first appears in the beginning of the sixth month, is not a constant formation, although I have met with it in the majority of the embryos I have examined (absent in the specimen reproduced in fig. 22). This little lamella develops into a small lobule, situated between the lobulus lunatus and the lobulus 
semilunaris, near the lateral border of the hemisphere and often protrudes into the fossa transversa.

From the middle of the sixth month onwards the lobulus semilunaris superior belongs almost entirely to the superior surface. Consequently the fissura horizontalis becomes the limiting groove between the superior and the inferior surface. The differentiation of the lobulus semilunaris superior begins at the end of the fifth month, with the formation of a large secondary groove, originating near the lateral border of the lobule.

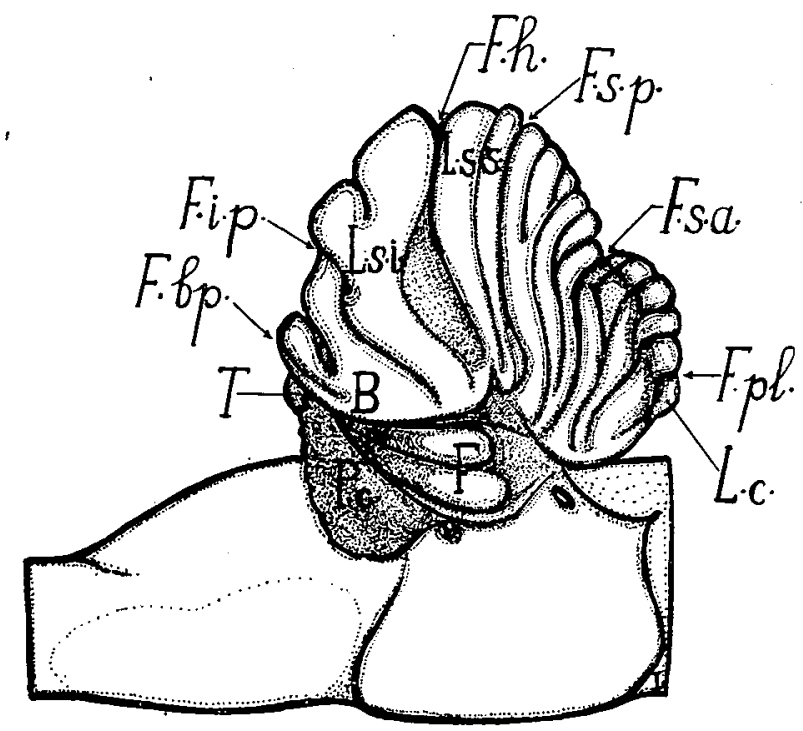

Fig. 23.-Isateral surface of a cerebellum of the beginning or of the middle of the sixth month. Same cerebellum as reproduced in figs. 20 and 21 . $B$, lobulus biventer; $F$., flocculus; $F . b p$., fissura bipartiens ; $F . h$., fissura horizontalis ; $F . i . p .$, fissura inferior post.; $F$.pl., fissura prelunata ; F.s.a., fissura superior ant.; F.s.p., fissura superior post. ; L.c., lobulus centralis; L.s.i., lobulus semilunaris inferior; L.s.s., lobulus semilunaris superior: $P . c .$, plexus chorioideus; T., tonsilla. Enlargement $\times 4$.

In the course of the sixth month this groove extends medially but remains strictly confined to the hemisphere. In the adult this secondary furrow can easily be recognized, because it divides the lobulus semilunaris superior into an anterior and a posterior division (figs. 22 and 23).

The lobulus semilunaris inferior also increases in size, especially along its lateral border. At the end of the fifth month, the first secondary groove appears, soon followed by two other grooves on either side of the first one, so that at the beginning of the sixth month the lobule is subdivided into four parts by three secondary 
grooves (fig. 24). The grooves take their origin in the median margin of the lobule and extend laterally. Shortly after, new secondary grooves arise in a somewhat irregular way, 'whereby the four sublobules are further split up (figs. 24 and 25, on the left).

The tuber which forms the union between the two lobuli semilunares inferiores lags somewhat behind in its expansion in comparison with the lateral lobules, and thereby gradually loses its connexion with the hindmost sublobules of the lobulus semilunaris. These hindmost sublobules which have lost their connexion with the tuber are often described as forming part of a separate lobe, the "lobulus gracilis."

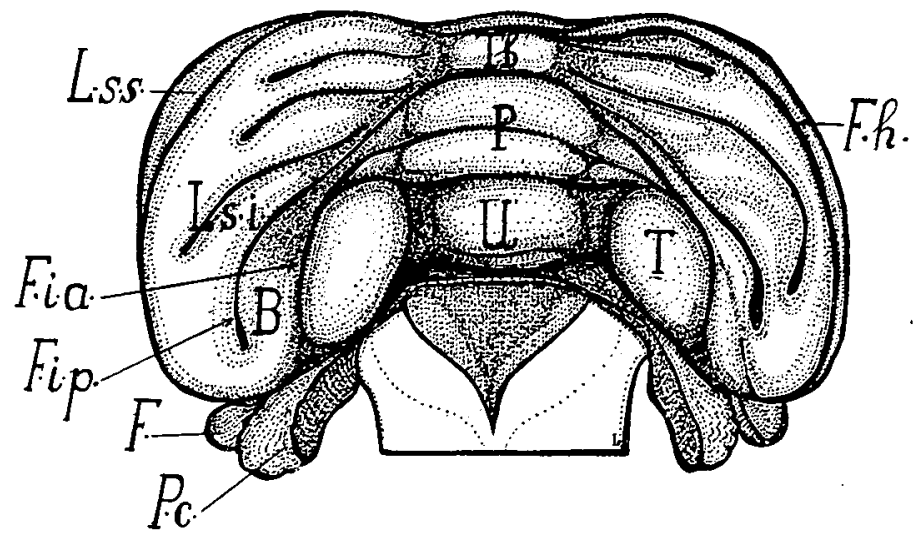

FIG. 24.-Inferior surface of a cerebellum of the beginning of the sixth month. Same cerebellum as reproduced in fig. $22 . \quad B$., lobulus biventer; $F$., flocculus; $F . h$., fissura horizontalis ; F.i.a., fissura inferior ant.; F.i.p., fissura inferior post. ; L.s.i., lobulus similunaris inferior; L.s.s., lobulus similunaris superior; $P .$, pyramis ; $P . c .$, plexus chorioideus ; $T$., tonsilla; Tb., tuber; U., uvula. Enlargement $\times 4$.

The mode of reconstruction and the final course of the fissura inferior posterior may show many variations. In the more simple cases, the lateral division of the groove forms the direct continuation of the medial divisions (fig. 24 on the left and fig. 25 on both sides). In other cases, the groove approaches the fissura inferior anterior in the neighbourhood of the top of the tonsilla, unites with the latter for a short distance and then reappears as a separate groove (fig. 24, on the right).

In the first case we find a lobulus biventer in direct connexion with the pyramis; in the second, the connexion is not manifest, and, if existing at all, the uniting bridge between pyramis and lobulus biventer lies concealed in the depth of the fissura inferior anterior.

The pyramis itself is divided by a deep secondary groove into 
two sublobules (fg. 24). This secondary groove also extends laterally into the lobulus biventer, subdividing this lobule into an anterior and a posterior division. On its way laterally, the groove often touches the tonsilla, joining over a short distance the fissura inferior anterior, and then reappears as a separate groove (fig. 25). The anterior division of the lobulus biventer, which is by far the smaller one, is often described as forming part of the lobulus gracilis. The conception, however, of a lobulus gracilis, composed of elements belonging to two different cerebellar lobes, seems to me erroneous. I should rather

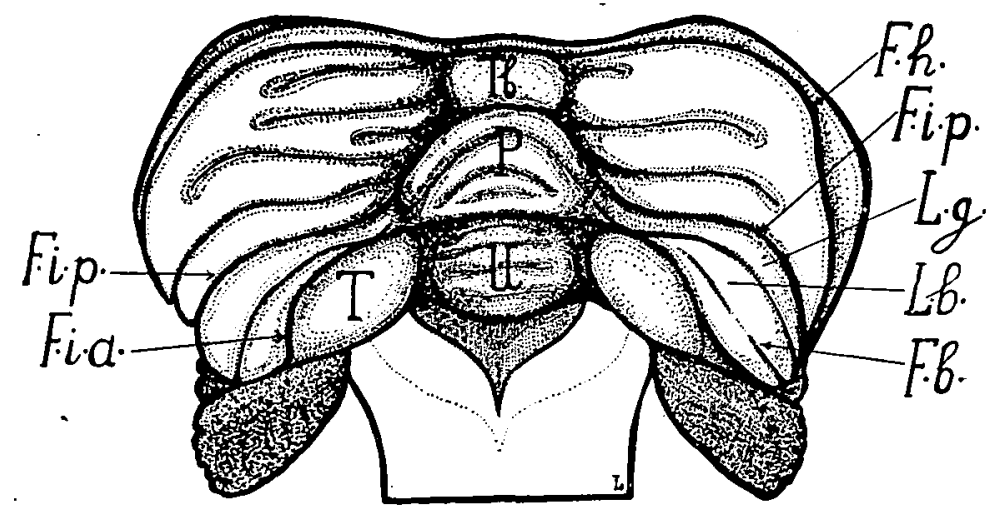

FIG. 25.--Inferior surface of a cerebellum of the beginning or of the middle of the sixth month. Same cerebellum as reproduced in figs. 20,21 , and 23 . $F . b$., fissura bipartiens; $F . h$, fissura horizontalis; F.i.a., fissura inferior ant.; F.i.p., fissura inferior post. ; L.b., lobulus biventer, s.s.; L.g., lobulus gracilis; $P .$, pyramis; T., tonsilla; Tb., tuber ; $U$., uvula. Enlargement $\times 4$.

be inclined to propose the denomination "lobulus gracilis" for the anterior divisions of the lobulus biventer, and "lobulus biventer sensu strictiori" or briefly, "lobulus biventer" for the posterior divisions of the lobe. In the adult form, however, it is often difficult, or evep impossible, to recognise the fissura inferior posterior, and in those cases the true limit between the lobulus gracilis and the lobulus semilunaris inferior cannot be assigned. The posterior division 'of the lobulus biventer, or the lobulus biventer s.s., is split up by a secondary groove, emanating from the lateral border of the lobule. This secondary groove, which may always be recognized in the adult stage, is described by Ziehen as the "sulcus bipartiens" (fig. 25, on the right).

The fissura inferior anterior, which separates the lobus pyramidobiventricus from the lobus uvulatonsillaris, flattens in the neighbourhood 
of the lateral pole of the tonsilla and vanishes. The disappearance of the groove is caused by the atrophy of the more lateral part of the lobus uvulatonsillaris. At first this part of the lobe narrows and forms a small bridge joining the tonsilla to the little lateral field. Gradually the small bridge and the little lateral field flatten and disappear. At the same time the tonsilla, and especially its lateral pole, becomes more prominent and sharply marked off.

The position of the tonsilla is also altered. The longer axis of the tonsilla, which at first runs transversely, approaches more and more an antero-posterior direction. From within the sulcus paramedianus, the valecula has oxiginated, and into this the tonsilla is pressed down by the expanding lobuli semilunares and biventer. The tonsilla, in this stage of development, shows no trace of secondary grooves, and it is only two or three weeks later that the first secondary groove appears, by which the tonsilla is divided into two sublobules (fig. 28, on the left).

The uvula is subdivided by a secondary groove into two lobules (fig. 24). This groove is situated near the posterior border of the uvula and is soon followed by other secondary grooves in a somewhat irregular way (fig. 25).

The fissura preuvularis, which forms the limit between the lobi uvulatonsillaris and nodulofloccularis, approacbes more and more the posterior margin of the inferior surface. In consequence of the atrophy of the greater part of the lobulus floccularis, the fissura preuvularis further flattens and disappears, so that this groove runs out in the neighbourhood of the lateral pole of the tonsilla. The extreme lateral part of the groove persists, and forms the anterior limit of the flocculus.

The lobulus nodulofloccularis can only be exposed to view by rolling outwards the posterior border of the cerebellum. In fig. 26 I reproduce such a preparation pertaining to an embryo of the beginning or of the middle of the sixth month. The nodulus is still connected with the flocculi by means of elongated triangular stalks. Vestiges of these stalks may persist in the adult state, forming the white brachium noduli. The nodulus is divided by two secondary grooves into three sublobules These grooves remain limited to the nodulus and do not extend into the stalks. The flocculus consists in this stage of development of only two sublobules, which begin to show the first traces of a further subdivision by grooves emanating from the lateral margin. On the left of fig. 26, the accessory flocculus is exposed to view by turning the flocculus a little aside.

The lobus nodulofloccularis is bordered from behind by the fissura 
prenodularis. The hemispherical part of this groove flattens more and more in the course of the sixth or seventh month in consequence of the atrophy of the corresponding part of the lobe. The atrophied part of the lobe is assimilated to the posterior medullary velum, and it is therefore from that moment on that the nodulus and the flocculus are united by the velum.

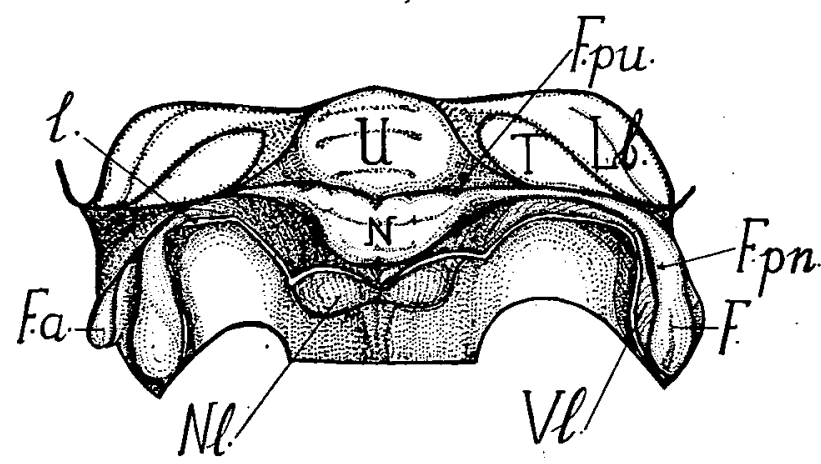

FIG. 26.-Posterior border of a cerebellum of the beginning or of the middle of the sixth month. Same cerebellum as reproduced in figs. $20,21,23$, and 25 . $F$., flocculus; $F$.a., flocculus accessorius; $F \cdot p n$., fissura prenodularis ; $F \cdot p u$., fissura preuvularis ; $l$, line along which the medullary velum is torn off ; $L . b$., lobulus biventer; $N$., nodulus; $N l$, , nodiolus ; $T$. , tonsilla; $U$., uvula ; Vl, velum medullare post. Enlargement $\times 4$.

The hemispherical division of the last lobe, the lobulus nodiolovelaris, is entirely atrophied, and only the vermis portion persists. This part forms what I have termed the nodiolus. The nodiolus is separated from the nodulus by the middle divisions of the fissura prenodularis. The atrophied part of the lobus nodiolovelaris is incorporated in the velum and partly transformed into the chorioid plexus. In the preparation reproduced in fig. 26 the plexus and the more atrophied parts of the velum have been removed. The line along which these parts are torn off still runs across the nodiolus. This relation is only intelligible if we remember that the transition of the cerebellar plate into the velum did not lie at the posterior margin of the plate, but a little anteriorly. In a later stage of development and also in the adult state, the transition of the velum into the cerebellum lies more in front, at the bottom of the fissura prenodularis (fig. 29). In that case the whole nodiolus protrudes freely into the ventricular cavity covered from the outside by the velum.

The nodiolus is still undivided, but in a somewhat older stage this structure is also split up by secondary grooves. In the same way as the nodulus, the nodiolus is laterally prolonged into two stalks, the brachia 
nodioli. These brachia form part of the velum, of which they represent a less atrophied part. The brachia nodioli sometimes persist in the adult state as small white tracts, running parallel to the brachia noduli. In fig. 27, I represent the nodiolus and its brachia from behind and also the connexion between velum and brachia by means of a frenulum.

In the course of the sixth month the fossa transversa is completed by the formation of the hindmost lip (figs. 22 and 23). This lip is chiefly formed by the lateral margin of the lobuli semilunaris inferior and biventer. Initially, the fossa transversa is a broad triangular depression, but by the expansion of the hemispheres the two lips approach each other, whilst the fossa narrows and becomes deeper. The top of the groove lies a little anteriorly in respect of the lateral extremity of the fissura horizontalis, and in most cases this relation is the persisting one.

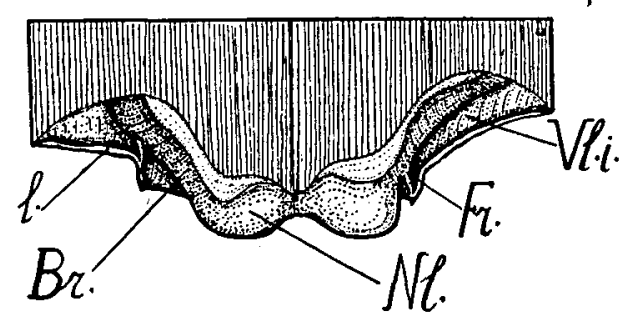

Fia. 27.-Pasterior border of a cerebellum of the beginning or of the middle of the sixth month. Ventricular aspect. Same cerebellum as reproduced in figs. 20, 21, 23, 25, and 26. $B r$., brachium nodioli : $F r$., frenulum; $l$, line along which the medullary velum is torn off. $\mathrm{Nl}$., nodiolus: Vl.i., velum medullare post., ventricular surface. Enlargement $\times 4$.

I end my description of the development of the external form with a cerebellum belonging to an embryo of the last half of the eighth month or perhaps slightly older.

The superior surface differs but little from the description already given. The number of lamellæ has increased by the formation of tertiary grooves, but the general feature of the surface has not changed. This is also the case with the inferior surface. This surface, by the increasing size of the hemispheres, approaches more and more the adult form. The folium has disappeared from the surface and in fig. 28 the connexion of the folium with the lobulus semilunaris lies concealed at the bottom of the fissura horizontalis.

The external surface of the tuber is subdivided into three lobules, which are connected with the three foremost sublobules of the lobulus semilunaris inferior. The posterior sublobules are for the greater part 
connected by means of white stalks with those lamellæ of the tuber which lie concealed in the depth of the fissura inferior posterior.

The pyramis is subdivided by a deep groove into two subdivisions. On the left, the anterior sublobule of the pyramis is in direct connexion with the anterior sublobule of the lobulus biventer (lobulus gracilis). On the right, this connexion is not manifest, and here it is the anterior part of the lobulus biventer s.s. which is connected with the foremost sublobule of the pyramis.

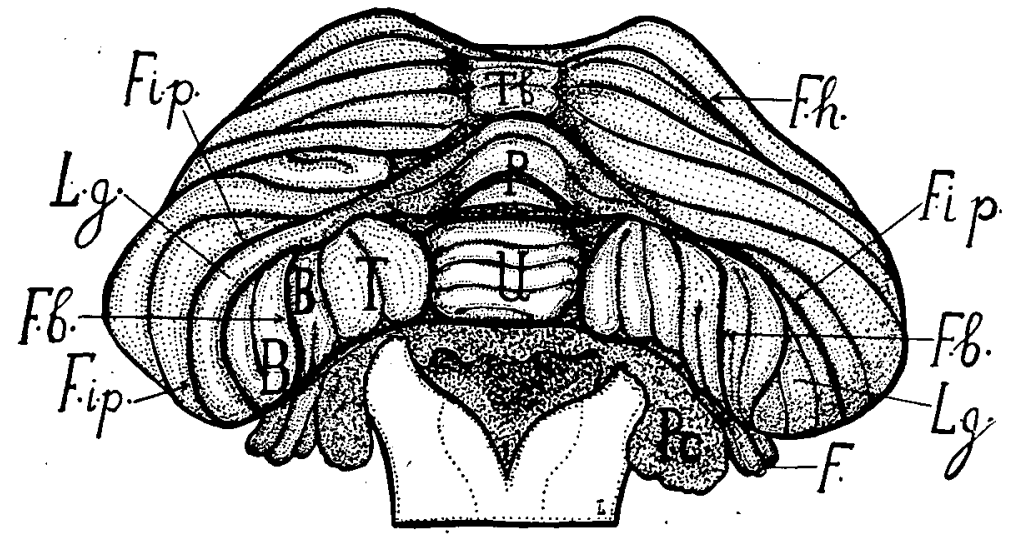

F1G. 28.-Inferior surface of a cerebellum of the last half of the eighth month. $B, B$, lobulus biventer, s.s.; $F$., flocculus ; $F . b$., fissura bipartiens : $F . h$., fissura borizontalis; F.i.p., fissura inferior post. ; L.g., lobulus gracilis ; P., pyramis ; P.c., plexus chorioideus ; $T$., tonsilla; $T b$., tuber; $U$., uvula. Enlargement $\times 3$.

The uvula becomes gradually triangular, being compressed laterally by the tonsillæ. Meanwhile, the valecula broadens and deepens, forming the niche in which the tonsillæ are embedded. In this specimen the left tonsilla is divided into two sublobules by a secondary groove, which becomes later the fossa axialis of Ziehen [23].

In consequence of the increased rolling inwards of the posterior border, the lobulus nodulofloccularis can only be exposed to view by cutting away the tonsillæ and the brainstem. Fig. 29 is the reproduction of the preparation after removal of the more atrophied parts of the velum and the chorioid plexus. Because the velum has only partly followed the rolling inwards of the posterior border of the cerebellum, this structure is reversed along the posterior margin of the flocculus. The line, along which the velum and the plexus are torn off, disappears at the lateral border of the nodulus in the depth of the fissura prenodularis, so that the nodiolus as a whole is covered by the velum. The 
nodiolus itself is rolled inwards and for that reason not visible in fig. 29. The brachia nodioli are atrophying, but still perceptible as white prominences on the inner surface of the velum. In this relation as well we approach the adult form.

' It seems evident from the description I have given here that the planning of a satisfactory scheme of the human cerebellum meets with many difficulties. The insurmountable obstacle lies in the fact that the cerebellum is neither a developable surface nor a surface that can be easily projected upon a plane. Every scheme of the human cerebellum is, therefore, not a schematic representation of the true form, but a

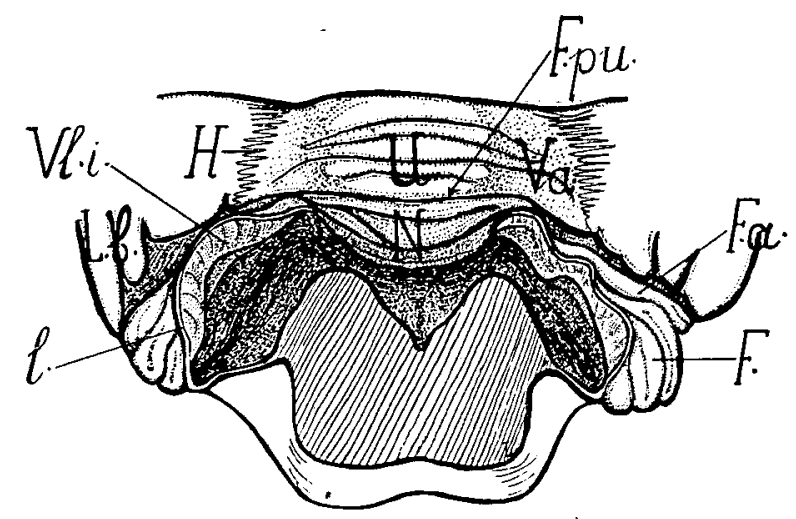

Fra. 29.-Posterior border of a cerebellum of the last half of the eighth month. Same cerebellum as reproduced in fig. 28 . $F$., flocculus ; $F . a$. , flocculus accessorius; $F \cdot p u$., fissura preuvularis; $H$, hilus tonsillæ; $l$, line along which the medullary velum is torn off; $L . b$. , lobulus biventer: $N$., nodulus; $U .$, uvula; Va., vallecula; Vl.i., velum medullare post., ventricular surface. Enlargement $\times 3$.

condensed graphic interpretation of facts which have only a remote relation to the observed form. Moreover, the scheme, which represents the cerebellum at the end of the first phase of its development, will be different from the scheme representing the cerebellum at the end of the second or of the third phase.

The scheme of Edinger [7] has the merit that it recognizes the vermis as a separate part of the cerebellum. The union, however, of the vermis with the flocculus into a new entity, the palæocerebellum, is not confirmed by my researches. This conception rests chiefly upon the fact that there are cases of unilateral affections of the nuclei pontis or of the middle peduncle, in which the vermis is intact and the hemisphere atrophied, with the exception of the flocculus. ${ }^{1}$ This fact

1 Brouwer [6] has given a description of such a specimen and also the literature on the subject. A little later Strong [21] published another case of this kind.I 
proves, however, not the intimate relation between vermis and flocculus but only that the chief connexions of the flocculus are not with the pons. ${ }^{1}$

Another merit of the scheme of Edinger is that it admits of a transverse subdivision of the cerebellum into lobes and that every lobe consists of an associated vermis and hemispherical division. The division by Edinger of the cerebellum into three principal lobes seems arbitrary, but nevertheless there exists some resemblance between the cerebellum at the end of the third month (figs. 7 and 8) and the scheme of Edinger.

The scheme of Bradley $[3,4]$ is not so simple as that of Edinger. $\mathrm{He}$ also recognizes the division of the cerebellum by purely transverse grooves, but in his scheme the vermis does not form a well-defined separate part. The division of the cerebellum into lobules resembles closely the division of the cerebellum of the first half of the fourth month (figs. 10 and 12), but the combination of these lobules into the five lobi A, B, C, D and E does not seem to be well founded. Especially the creation of a lobus $\mathrm{C}$, composed by the lobi declivolunatus, foliosemilunaris and tuberosemilunaris, as well as the conception of a lobus $\mathrm{D}$ built up by the lobi pyramidobiventricus and uvulatonsillaris, does not seem in harmony with the facts observed in the human cerebellum.

In the scheme of Smith $[17,18]$, the fact seems incorporated that for a short time the furrowing of the vermis and of the hemispheres occurs independently, especially in the central zone of the cerebellum. Another merit of this scheme is the creation of a large area ptereoidea and post-ptereoidea. In these features the scheme of Smith would probably agree with a stage of development intermediate between the stages represented in figs. 8 and 10 . Smith disregards, however, the fact that even in the central zone of the cerebellum the fissures of the vermis and of the hemispheres finally meet, forming complete transverse fissures. ${ }^{2}$ Consequently, the Smith scheme has the disadvantage of not recognizing that the whole cerebellum, and not only his lobus anterior, is built up by transverse lamellæ. On this account the scheme is not fully applicable to the case of the human cerebellum.

More complicated and still less applicable to human relations is the scheme of Bolk [2]. In many respects this scheme resembles that of Smith. His conception of a lobulus ansiformis, and especially of a

1 Experiments of Bárány [1] and others prove that the flocculus is in close connexion with the vestibular system.

2 With the exception in some cases of the fissura horizontalis. 
formatio vermicularis, as morphological entities, is not to be reconciled with the primary division of the human cerebellum by complete transverse fissures into ten separate lobes. Hence it seems impossible to recommend the application of the nomenclature of Bolk to the human cerebellum.

\section{BIBLIOGRAPHY.}

[1] Báráky, R. "Untersuchungen über die Funktion des Flocculus am Kaninchen," Jahrb. f. Psych. u. Neurol., 1914, Bd. xxxvi, S. 631.

[2] Bork, L. " "Das Cerebellum der Säugetiere," "Petrus Camper," Dl. iii, p. 1.

[3] Bradley, O. Charnock. "On the Development and Homology of the Mammalian Cerebellar Fissures," Journ. Anat. and Physiol., 1903, vol. xxxvii, new series, vol., xvii, pp. 112 and 221.

[4] Idem. "The Mammalian Cerebellum," ibid., 1904, vol. xxxviii, new series, vol. xviii, p. 448 ; and 1905, vol. xxxix, new series, vol. xix, p. 99.

[5] Idem. "On the Development of the Hind.brain of the Pig," ibid., 1906, vol. xl, third series, vol. i, pp. 1 and 133.

[6] Brouwer, B. "Ueber Hemiatrophia neocerebellaris," Arch. f. Psych. und Nervenkrankh., 1913, Bd. li, S. 539.

[7] EnInger, L. "Ueber die Entwicklung des Cerebellums," Anat. Anz., 1910, Bd. xxxv, S. 319 .

[8] Hente, J. “ Handbuch der Nervenlehre des Menschen," 1e Aufl., Braunschweig, 1871.

[9] Hız, W. "Die Entwicklung des menschlichen Rautenhirns, Abh. Math.phys. Cl. der K. Säsh.," Gesell. der Wissenschaften, 1891, Bd. xvii, S. 1.

[10] KöLliker, A. "Entwicklungsgeschichte des Menschen und der höheren Thiere," 2e Aufl., Leipzig, 1879.

[11] Kutrhan, W. "Die Entwicklung des Kleinhirns bei Säugetieren," Münch. Med., Abh., 1895, vii Reihe, 6te Heft, S. 1.

[12] LanghlaAn, J: W. " On a Stage in the Development of the Human Cerebellum," Anat. Anz., 1908, Bd. xxxii, S. 421.

[13] Minalikovics, V. von. " Entwicklungsgeschichte des Gehirns," Leipzig, 1877.

[14] Rexzius, G. "Das Menschenhirn," i, Stockholm, 1896.

[15] SсHÄFer, E. A. "The Spinal Cord and Brain," "Quain's Elements of Anatomy," London, 1902, vol. iii, part i, p. 69.

[16] Schwalbe, G. "Lehrbuch der Neurologie," Erlangen, 1881.

[17] Sмiтн, G. Eсціот. "Notes on the Morphology of the Cerebellum," Journ. Anat. and Physiol., 1903, vol. xxxvii, new series, vol. xvii, p. 329.

[18] Idem. " Further Observations on the Natural Mode of Subdivision of the Mammalian Cerebellum," Anat. Anz., 1903, Bd. xxiii, S. 368.

[19] Idem. "The Morphology of the Human Cerebellum," Rev. Neurol. and Psych., 1903, vol. i, p. 629.

[20] Streeter, G. L. “Die Entwickelung des Nervensystems," "Handb. Entwickelungsgeschichte des Menschen," Leipzig, 1911.

[21] Strong, O. S. "A Case of Hemicerebellar Atrophy in a Child," Proc. Amer. Assoc. Anat., Philadelpbia, December 30, 1913.

[22] Stroud, B. B. "The Mammalian Cerebellum," Journ. of Comp. Neurol., 1895, vol. v, p. 71.

[23] Zienen, Th. "Anatomie des Nervensystems," Lief 10, "Handbuch des Anat. des Menschen," Jena, 1903, S. 444. 